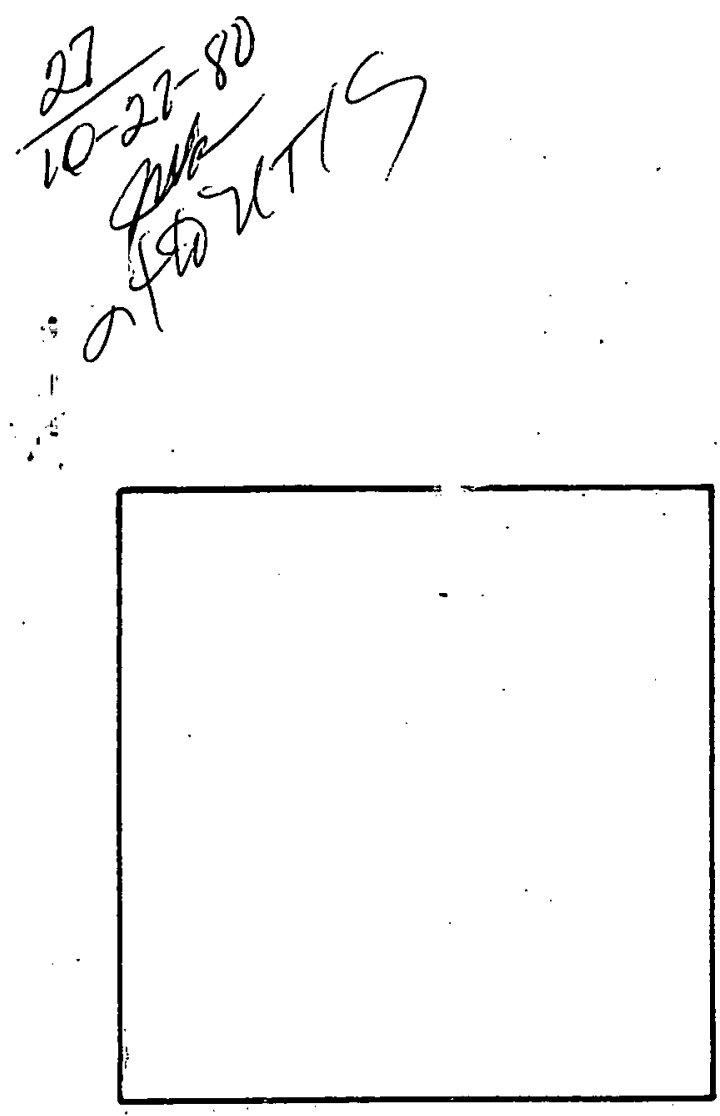

BDX-613-2482

\title{
Experimental Modeling of
} Laminar Composites for Multifrequency Eddy Current Measurements

MASTER

\author{
By R. V. Heckman
}

Published August 1980

Milestone Report

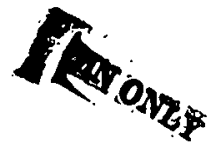

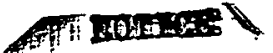

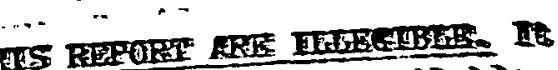

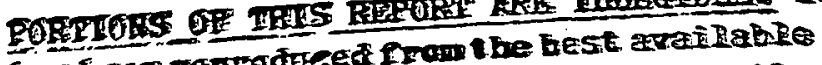

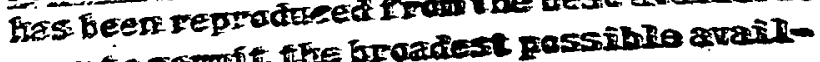
coty to perutitifise

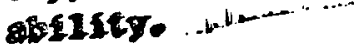

Prepared for the United States Department of Energy Under Contract Number DE-AC04-76-DP00613. 


\section{DISCLAIMER}

This report was prepared as an account of work sponsored by an agency of the United States Government. Neither the United States Government nor any agency Thereof, nor any of their employees, makes any warranty, express or implied, or assumes any legal liability or responsibility for the accuracy, completeness, or usefulness of any information, apparatus, product, or process disclosed, or represents that its use would not infringe privately owned rights. Reference herein to any specific commercial product, process, or service by trade name, trademark, manufacturer, or otherwise does not necessarily constitute or imply its endorsement, recommendation, or favoring by the United States Government or any agency thereof. The views and opinions of authors expressed herein do not necessarily state or reflect those of the United States Government or any agency thereof. 


\section{DISCLAIMER}

Portions of this document may be illegible in electronic image products. Images are produced from the best available original document. 
This report was prepared as an account of work sponsored by the United States Government. Neither the United States nor the United States Department of Energy, nor any of their employees, nor any of their contractors, subcontractors, or their employees, makes any warranty, express or implied, or assumes any legal liability or responsibility for the accuracy, completeness or usefulness of any information, apparatus, product or process disclosed, or represents that its use would not infringe privately owned rights.

Printed in the United States of America

Available From the National Technical Information Service, U.S. Department of Commerce, 5285 Port Royal Road, Springfield, Virginia 22161.

Price: Microfiche $\$ 3.00$

Paper Copy $\$ 4.50$ 
EXPERIMENTAL. MODELING OF LAMINAR COMPOSITES .FOR MULTIFREQUENCY EDDY CURRENT MEASUREMENTS

By R. V. Heckman

Published August 1980

Milestone Report

R. V. Heckman, Project Leader

Project Team:

W. J. Bowden

H. E. Pease

D. E. Lacey
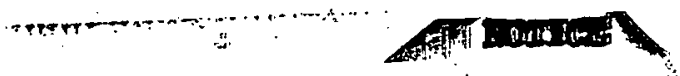

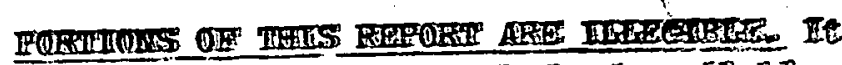

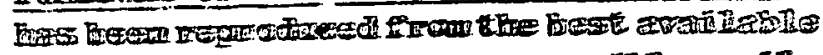

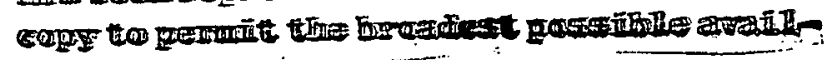
athonthe

Technical Communications

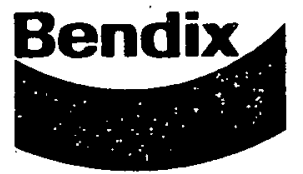

\section{Kansas City Division}

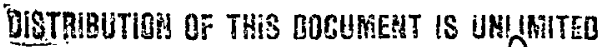


EXPERIMENTAL MODELING OF LAMINAR COMPOSITES FOR MULTIFREQUENCY EDDY CURRENT MEASUREMENTS

BDX-613-2482, Milestone Report, Published August 1980

Prepared by R. V. Heckman

This report describes a computer modeling program, originally developed by Dodd and Deeds of Oak Ridge National Laboratory, capable of calculating the experimental voltage amplitudes and phases which can be obtained with rectangular cross-section coils being operated at multiple frequencies. This program was applied to two multilayered composites in order to determine the feasibility of making thickness and resistivity measurements of the individual layers. The results of these calculations indicate that the thickness of the aluminum/Kapton composite layers could be measured to a precision of better than one percent and the resistivity of the conductive layers could be measured to a precision of better than 10 percent. The second composite, a structure consisting of alternating layers of aluminum and polyimide, a varnish, was found to be measureable also. A minimum of two frequency components were found to be necessary for the aluminum/Kapton composite while three frequencies were found to be necessary for the aluminum polyimide case.

DC/srg

This report was prepared as an account of work sponsored by the United States Government. Neither the United States, nor the United States Department of Energy, nor any of their employees. nor any of their contractors, subcontractors, or their employees, makes any warranty. expressed or implied or assumes any legal liability or responsibility for the accuracy, completeness or usefulness of any information, apparatus, product, or process disclosed, or represents that its use would not infringe privately owned rights.
The Bendix Corporation Kansas City Division P. O. Box 1159 Kansas City, Missouri 64141

A prime contractor with the United States Department of Energy under Contract Number DE.AC04-76-DPO0613 


\section{CONTENTS}

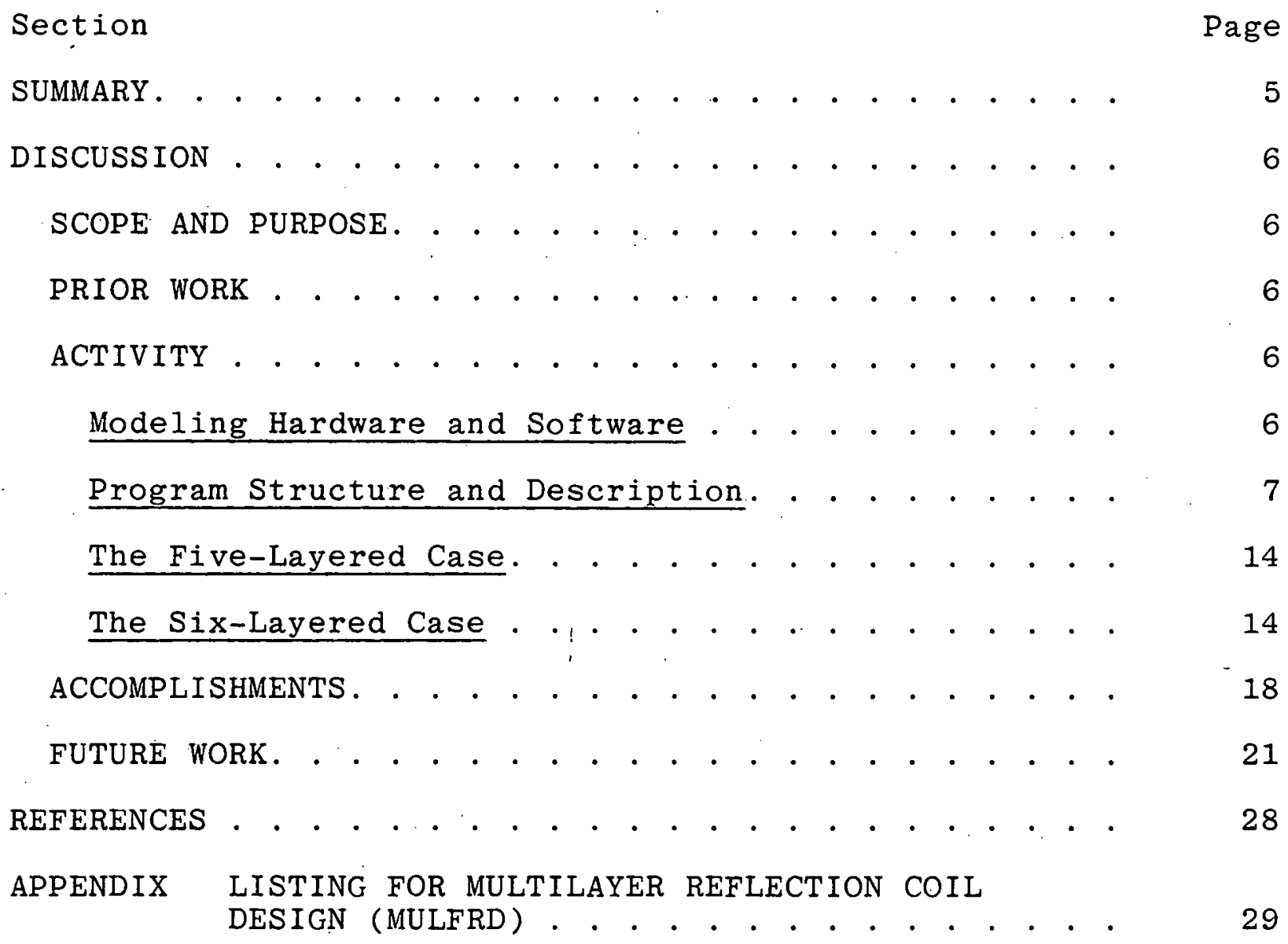




\section{ILLUSTRATIONS}

Figure

Page

1

Schematic Representation of the FiveLayered Composite. . . . . . . . . . . . .

Schematic Representation of the SixLayered Composite. . . . . . . . . . . .

Sample Printout of the Input for MULFRD Showing the Selection of a Particular Property in a Specified Layer Using Various Polynomials for Best Fits of Magnitude and Phase. . . . . . . . . . . . . . .

\section{TABLES}

Number

Page

Summary of Editorial Changes Preparatory to Running MULFRD . . . . . . . . . . . . .

Definition of Program Mnemonics Used for MULFRD . . . . . . . . . . . . . . . .

Property Values and Ranges Used for Modeling the Five-Layered Composite. . . . .

Dimensional and Electrical Properties for Eddy Current Coils . . . . . . . . . . . .

Summary of Five-Layer Calculations Using 20-C and 40-A Probes. . . . . . . . . .

Property Values and Ranges Used for Modeling the Six-Layered Composite. . . . . . . . . 


\section{SUMMARY}

The goal of this project is to devise nondestructive techniques for measuring the thickness and conductivities of the individual layers in multi-layered laminar composites. The theoretical expressions for the vector potential, A, and the output voltage, $V$, were derived earlier. In this report these expressions are solved using computer techniques for two composite structures of interest. The first composite examined is a planar structure consisting of a $0.01524 \mathrm{~cm}$ aluminum substrate coated with alternating layers of an insulating material nominally $0.0037 \mathrm{~cm}$ thick and physical vapor deposited aluminum nominally $0.0025 \mathrm{~cm}$ thick. The complete laminate was made up of two alternating layers of polyimide insulator and two layers of physical vapor deposited (DVD) aluminum. The second system that was modeled, consists of an aluminum substrate $0.01524 \mathrm{~cm}$ thick, an insulator layer of $0.0028 \mathrm{~cm}$ Kapton, a physical vapor deposited layer nominally $10.0 \mu \mathrm{m}$ thick, and a top insulator covering of $0.0028 \mathrm{~cm}$ Kapton. The theoretical values of phase and amplitude were calculated for these composites using various combinations of frequency and for different size probes. The calculations enabled an estimate to be made of the ability of a given probe/frequency combination to determine a particular laminate parameter, such as layer thickness, or layer resistivity. The programs also estimate the accuracy of these measurements and predict the effect of 1 percent variations in the various instrument parameters. 
DISCUSSION

SCOPE AND PURPOSE

A nondestructive method of measuring individual layers of thickness and/or resistivity for multilayered laminates was required. The scope and purpose of this project is to develop appropriate nondestructive techniques to accomplish these measurements.

Multifrequency eddy current techniques appear capable of meeting these requirements. This technique developed by $C$. V. Dodd and W. E. Deeds is now being applied by Bendix Kansas City. Equipment based on Dodd's design has been assembled and is now being evaluated. To determine feasibility of these measurements, software developed by Dodd and Deeds has been applied to the laminar composites which closely model the structure of the actual systems. The initial settings used on the prototype hardware will be based on the output of these modeling programs. A PDP-11/34 computer system and an Intel Model 232 Intellec System have been received to permit a comparison of experimental values with the theoretical calculated values obtained from the modeling software. The results of this comparison will be covered in future reports on this project.

\section{PRIOR WORK}

This work represents a continuation of the work reported in Simultaneous Measurement of Multilayered Composites, BDX-613-2176, September, 1979. This project is based on work and equipment designed and built by $C$. V. Dodd and W. E. Deeds of Oak Ridge National Laboratories, ORNL, consultants on this project.

\section{ACTIVITY}

Modeling Hardware and Software

The software used on this project is written in FORTRAN IV compatible with the FR4 Compiler of a MODCOMP Max IV System Processor. As part of this project this software is being edited to be compatible with DEC FORTRAN IV. One subroutine, READAT, and one main program, RFLRDG, includes short sections of MODCOMP IV Assembly Language.

Since Bendix does not have any MODCOMP hardware and since time was of the essence, the activities described in this report were 
performed at Lawrence Livermore National Laboratories (LLNL), with the assistance of Edward Leubke, program specialist, who edited the existing program to conform with the architecture of the LLNL system and resolved the compatibility problems encountered with the media supplied.

\section{Program Structure and Description}

The software is structured so that the entire modeling process consists of four steps.

1. Determination of the optimum probe/frequency values,

2. Comparison of these optimum theoretical values with experimental values,

3. Interpolation between the theoretical and experimental values to obtain the samples from the measured readings, and

4. Using these calibration constants to calculate the properties of unknown samples from measured readings.

In this report the first phase of this process was performed for the two laminates shown in Figures 1 and 2. The program associated with this phase is titled MULTILAYERED REFLECTION COIL DESIGN (MULFRD). A listing of this program is included as Appendix A.

Considerable editing must be performed prior to executing MULFRD. The most complex task in this editing process is to determine the proper dimensions for the various arrays, and to accurately construct all of the unique property sets associated with the problem of interest. As an example let us consider the fivelayered case shown in Figure 1. The outside layer, layer five in this case, is always taken as free space, and the innermost layer, layer one, is always the substrate. In this particular case layers two and four are insulators and layer three is a conductor (aluminum). If we select two values of thickness for layers two through four, and two values of resistivity for layer three, then there will be 24 unique property sets. In this example we have not assumed any defects. If defects are included then another array must be constructed which includes the defect parameters. A program is now being written that will construct these arrays automatically. If the arrays are made too large or too small then invalid results will be obtained from running the program; therefore, care should be taken to make sure this step is performed correctly.

Considerable additional editing must be performed before the program is ready for execution. This editing is shown in tabular 


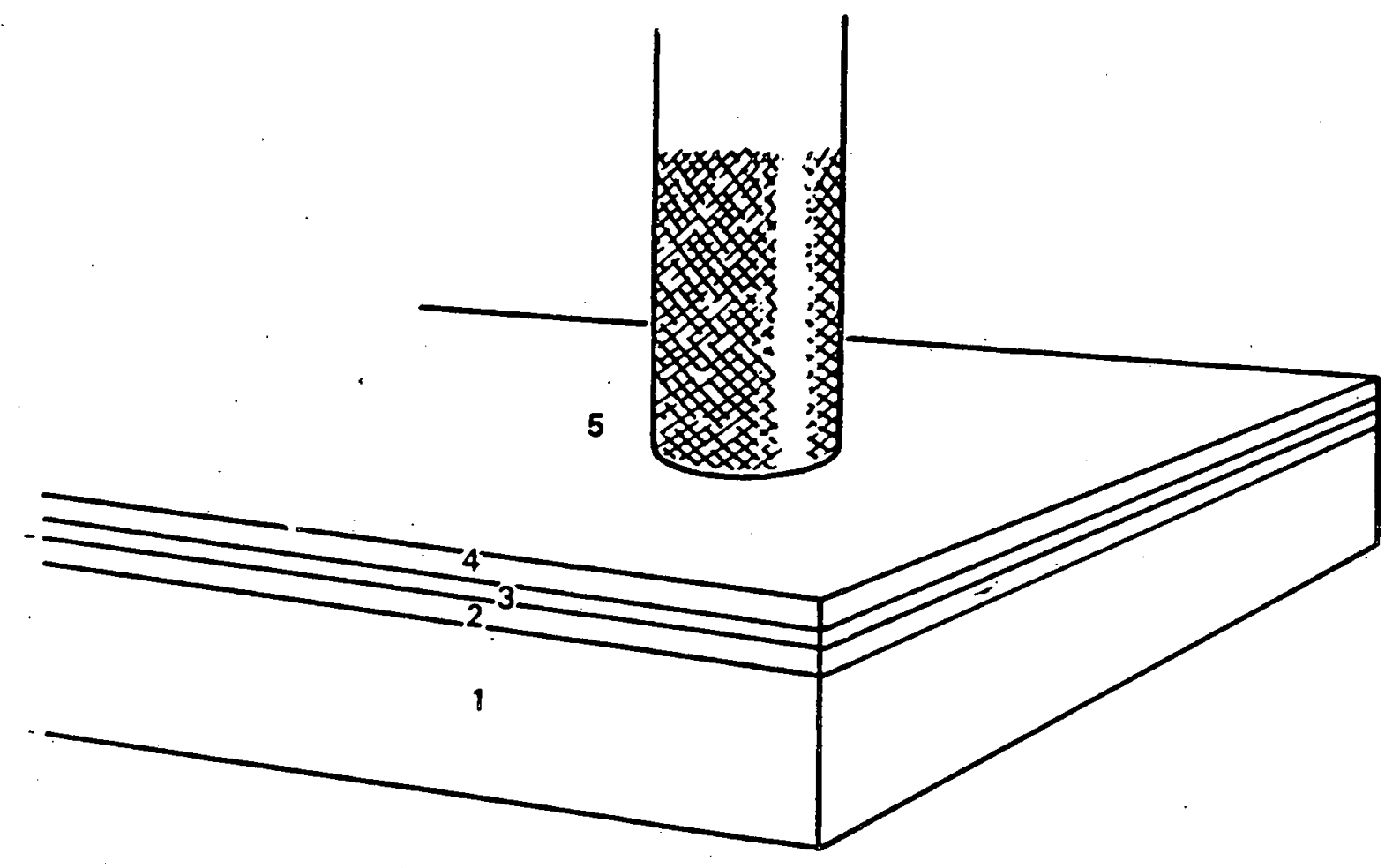

Figure 1. Schematic Representation of the Five-Layered Composite

form in Table 1. A listing of the program's many mnemonics is given in Table 2. In this report the two cases treated are assumed to be defect free; however, it should be noted that MULFRD is structured to allow the simulation of defects anywhere in the laminate. Using the MODCOMP IV, the execution times for running MULFRD for the two cases considered in this report was 20 minutes for the five-layered case and 1 hour and 20 minutes for the six-layered case. The execution times for the same cases using the PDP $11 / 34$ without a hardware floating point processor were respectively; 2 hours and 30 minutes for the five-layered case, and 5 hours for the six-layered case. A floating point processor was purchased for the PDP 11/34, and hopefuliy with this addition the execution times for these programs can be reduced to times compatible with the MODCOMP IV times.

After MULFRD has completed execution, several options can be performed. A printout of the system parameters, the property matrix, and the calculated phase and magnitude values can be obtained with option one. Option two allows the operator to try various polynomial fits of the calculated data. Option three obtains a comparison of the values that were initially input with values calculated using the polynomial fit developed under option 


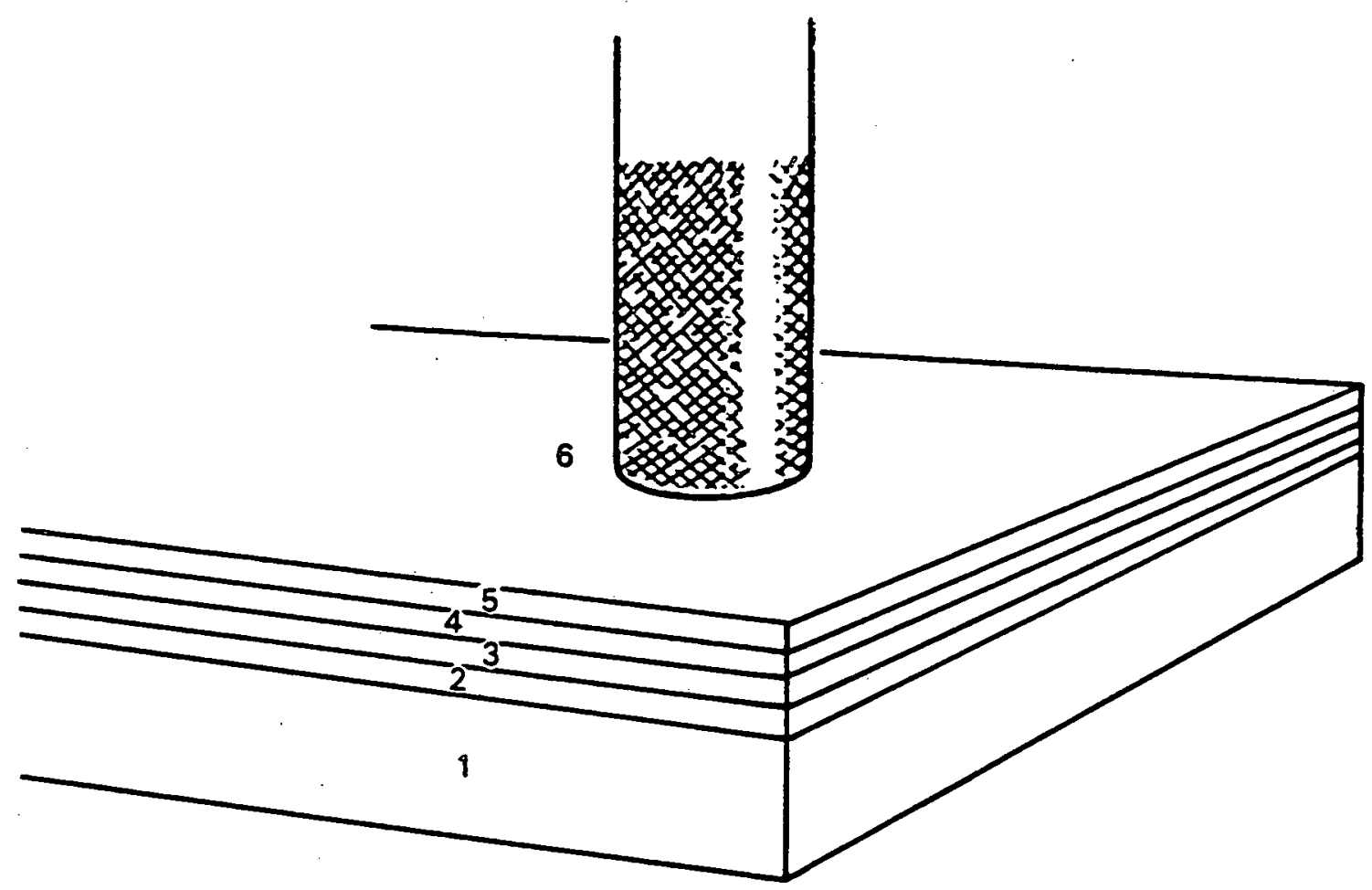

Figure 2. Schematic Representation of the Six-Layered Composite

two. Option four converts the decimal values for the polynomial fit obtained in option two to a hexadecimal value suitable for the NDT COMP 8 microprocessor. Option five permits changing the fit function. Options six and seven enable changing the circuit and coil parameters respectively. Option eight permits the calculation of the effect of circuit draft on magnitude and phase. Finally option nine stops execution of the program.

Of all these options, option two requires some further comment. This option is most extensively used for design purposes.

Various functions of linear, exponential, logarithms, or inverse functions can be specified with powers to the 15 th order, and with varying numbers of crossterms. In practice one should start with the linear function, and in general, powers of greater than 2 should be used only when necessary. The problem with higher order functions is that redundant solutions and discontinuities might occur in the region of interest. If a satisfactory fit cannot be obtained with either a first or second order function, the number of values chosen in the range of interest for each parameter should be increased to assure that the function is in fact continuous and does not have redundant solutions in the 
Table 1. Summary of Editorial Changes Preparatory to Punning MULFRD

\begin{tabular}{|c|c|}
\hline Line (s) & Actions \\
\hline 7 & Adjust array dimensions; follow key provided. \\
\hline $30-36$ & $\begin{array}{l}\text { Adjust control parameters (NRT, NPT, NFT, NDFLOC, NDSIZ; } \\
\text { select initial identifier (Probe). }\end{array}$ \\
\hline 3137 & $\begin{array}{l}\text { Select print option (NPRINT), output device (LOU), input } \\
\text { device (LI), (NPRINT }=0 \text {, no initial property or circuit } \\
\text { tables). }\end{array}$ \\
\hline $44,32,7$ & $\begin{array}{l}\text { Enter defect parameter values (free format) } \operatorname{NRDF}(J) \text {; } \\
\operatorname{DFDP}(J) \text {. }\end{array}$ \\
\hline 39 & $\operatorname{DFRAD}(J) ;$ DFDIAM = single value. \\
\hline $22-24$ & Enter property values (free format). \\
\hline 25 & Enter frequency values (free format). \\
\hline 26 & $\begin{array}{l}\text { Enter gain values (free format) in same order as } \\
\text { frequencies. }\end{array}$ \\
\hline 49 & Enter normalized lift-off increment (free format) L2. \\
\hline $58-62$ & Enter initial set of circuit parameters (free format). \\
\hline
\end{tabular}

region of interest. To select the property the operator first specifies the property of interest and then the region of interest. The program provides a menu to assist in this selection. Next a trial polynomial is entered specifying the functional dependence, the order of the function, and the number of crossterms. For example, 2,2,0 specifies a logarithmic function of second order with no crossterms. Functional dependences are specified for each amplitude and phase. A sample printout of this process is shown in Figure 3 . In this example, a twofrequency problem is presented. The property and region are centered using the menu format. (i.e. 3,2 would be thickness [3], layer 2.) After a functional dependence is specified for each value of phase and amplitude, the program calculates the cumulative standard deviation for the parameter being measured together with an estimate of the draft which could be anticipated from the instrument. Various polynomials are tried until this standard deviation value is reduced to an acceptable level. In practice, the drift value should be small as compared to the standard 
Table 2. Definition of Program Mnemonics Used for MULFRD

Control

Parameter Definition

DFDP

Initializing data; mean depth of center of a surface defect (inches) measured from the surface ${ }^{a}$ of the layer in which the defect is embedded. (This number is not used for computation.)

DFLOC Vertical distance of defectb below top of layer (inches).

DFRAD Radial distance of defect (center of sphere) from driver-coil axis (inches), fixed at $0.0832 \mathrm{~F}_{5}$, unless the problem requires consideration of multiple defects with offsets in radial distance.

DFDIAM Diameter (inches) of sphere with volume equal to that of actual defect,

$$
\frac{6 \text { (defect volume) }}{\pi} 1 / 3
$$

DFVOL Normalized defect volume,

$$
\frac{\pi}{6} \quad \frac{\text { DFDIAM }}{R_{5}} \text {. }
$$

IRDPRM Maximum number of coefficients allowed in the least squares fitting expansions; typically set at 15 .

LI

Logical input unit; transmits operator commands to computer.

LOU

Logical output unit; supplies cue statements and printed output to operator.

NCOIL Sequential position index of coil data in File 28. (Local compiler requirement for direct access file statements.)

NDFLOC Initialized data; number of step values for defect location, DFLOC.

NDFSIZ Initialized data; number of step values for defect size, entered as DFDIAM; normaliy set at 1 . Can be set greater than 1 to check linearity, but further editing would be required. 
Table 2 Continued. Definition of Program Mnemonics Used for MULFRD

Control

Parameter Definition

NDPS NDFLOC*NDFSIZ (line 113). Product equals the number of unique defect property sets in a specimen as MULFRD is now written.

NFT Number of discrete frequencies for which computations are performed.

NLT Number of values of driver-coil lift-off for which computations are performed.

NODF The number of unique property sets obtained by combining defect properties and conductor properties and accounting for all step variations ("combined" property sets).

NPRINT Print and transfer index; initial value selects printing of tabular output. Values selected during execution determine selected program options.

NPT The number of unique conductor property sets; includes the number of conductor properties and the steps of variation in each property.

NPTT. The number of combined property sets, including defects as distinct property sets. (The total number of calculations required by conductor and defect properties.)

NRT Number of regions in the problem, including the air region containing the coil.

NUNIT Unit control. Initial value selects English or metric output length dimensions. ( 1 = English, 2 = metric.)

"Top" is the driver-coil side of the layer.

${ }^{b}$ Coordinate locations of normalized defect refer to center of sphere representing the defect. 
SEECT NUMBER OF THE PROPERTY TO EE FITTED:

1=RHD 2=MU 3-THIONESS 4-LIFT-OFF 5-DEFECT LOCAT 6-DEFECT SIZE

SEICT REGION TO BE FITTED. LOWEST IS NUMBER 1.

3,3

TMPE 1 IF THERE IS OFFSET, $\theta$ IF ND OFFSET:

0

SEECT THE MUMER OF THE FUNCTION TYPE, POLNNOMIAL DEGRE, \& \& OF

CROSS TERMS FOR EAOH MAONITUDE \& PHASE

FUCTION TYPE: 1=LINEAR 2=LOG 3-EXP 4=INN

FCTN PQ + CROSS

TYPE DEG TEPMS

MAG AT 2.000000E+BS HR

$2,2,0$

PHA AT 2.8000005+65 HR

$1,2,0$

MAG AT 1.000000E+OS HZ

2, 2,0

PHA AT 1.000000E+Q6S HR

$1,2,8$

PQLPRY.

(LOG M1)1

(LOG MI)Z

(LIN P1)1

(LIN P1)2

(LOG MR)1

(LOG MR)2

(LIN P2)1

(LIN PQ)2

DIFF IN THIK IN MN IN REG * 3* 0.00493 DRIFT- 0.00001

TYPE NUMEER OF NEXT ACTION TO EE TAKEN:

1-PRT PROPS; 2-FIT PROP; 3=PRT ENTIRE FIT; 4-PRT COEF; 5-CHG FCTNPA TYP

6"CHG COILAKT VAL;7"CHE W PRT;8=CAL COIL/OKT DRIFT;9=STOP

Figure 3. Sample Printout of the Input for MULFRD Showing the Selection of a Particular Property in a Specified Layer Using Various Polynomials for Best Fits of Magnitude and Phase

deviation value. When these requirements are met, then option three is used to obtain a complete printout of the property fit. Using this option, the calculated value of the property of interest is compared to the input value and the difference is calculated. If this fit appears good, i.e. the differences are all small, then the calculated coefficients obtained are ready to be loaded into the microprocessor (NDT COMP8). 
A schematic representation of this composite is shown in Figure 1. The desired precision for the measurement of layer thickness is on the order of 1 percent, and the precision for the measurement of the resistivity of the aluminum layer is on the order of 10 percent. The thicknesses were input in terms of inches, while resistivity was entered as $\mu \Omega \cdot \mathrm{cm}$, and permeability as a unitless quantity. The values chosen for thickness, resistivity, and permeability of each layer are given in Table 3. Using these property values, the 24 property sets shown in Figure 4 were obtained. For simplicity's sake, the assumption was made that no defects existed, therefore the defect columns are all blank. The program MULFRD was run using several combinations of frequencies; the lower frequency being between 100 and $500 \mathrm{kHz}$ while the high frequency was fixed at $1 \mathrm{MHz}$. It was found that the best results were obtained at $200 \mathrm{kHz}$. Runs were made using the 20-C and 40-A probes. Probes are named according to their mean radius in $\mathrm{mm}$ with a suffix of $\mathrm{A}, \mathrm{B}$, or $C$ specifying the amount of built-in liftoff. Thus, a $20-\mathrm{C}$ probe is $20 \mathrm{~mm}$ in diameter and has more liftoff than say a 20-A probe. The dimensional and electrical properties of these two coils can be found in Table 4. A gain of 30 was used for the low frequency component and a gain of 10 was arbitrarily chosen for the high frequency component. In general, the gain for lower frequency components should be set higher than the high frequency components.

With these parameters, the best fit polynomial was obtained for the layers of interest, namely layers two, three, and four (layer one is the substrate and layer five is free space). A summary of the results of this process is given in Table 5. As seen in this table, both the 20-C and the 40-A probe produced acceptable results; however, the estimated drift for the 40-A probe was for most cases less than the drift obtained with the 20-C probe.

On the basis of these measurements it was concluded that either the 20-C or 40-A probe driven with frequencies of $200 \mathrm{kHz}$ and. $1 \mathrm{MHz}$ could successfully measure the thickness of each insulator and conductor layer and could also measure the resistivity of the center aluminum conductor. The polynomials developed will be used to program the NDT COMP 8 for the first experimental measurements. The comparison of the experimental values with the theoretical values computed in this report will be made in the next Milestone Report.

\section{The Six-Layered Case}

A schematic of the six-layered composite that was investigated is shown in Figure 2. The required precision for thickness and resistivity were less stringent for this case than for the fivelayered composite discussed above; namely 3 percent for the 
Table 3.. Property Values and Ranges Used for Modeling the Five-Layered Composite

\begin{tabular}{llll}
\hline Layer & $\begin{array}{l}\text { Thickness } \\
(\text { inches })\end{array}$ & $\begin{array}{l}\text { Resistivity } \\
(\mu \Omega \cdot \mathrm{cm})\end{array}$ & Permeability \\
\hline 1 & 0.005 & 5.24 & 1 \\
2 & 0.0080 & $1 \times 10(10)$ & 1 \\
& 0.0085 & $1 \times 10(10)$ & 1 \\
3 & 0.00042 & 2.57 & 1 \\
& 0.00042 & 2.60 & 1 \\
& 0.00048 & 2.57 & 1 \\
& 0.00048 & 2.60 & 1 \\
4 & 0.0030 & $1 \times 10(10)$ & 1 \\
& 0.0032 & $1 \times 10(10)$ & 1 \\
5 & $1 \times 10(10)$ & $1 \times 10(10)$ & 1 (free space) \\
& & &
\end{tabular}

thickness measurement and 10 percent for the resistivity measurement. The property set for this case is shown in Table 6 . Again, the assumption of no defects was made. Runs of MULFRD were initially made using two frequencies. It was found that with two frequencies there were not sufficient independent variables to distinctly measure all thicknesses and resistivities. MULFRD was then executed using three frequencies. Values of frequency were chosen in the range from $100 \mathrm{kHz}$ to $1 \mathrm{MHz}$. The best results were obtained using 100 and $200 \mathrm{kHz}$, and $1 \mathrm{MHz}$ with gains of 100,30 , and 10 respectively. The greatest sensitivity was obtained using a 20-C probe (See Table 4 for probe properties). A summary of the results obtained using the 20-C and 40-A probes operated at frequencies of 100 and $200 \mathrm{kHz}$, and $1 \mathrm{MHz}$ is presented in Table 7 .

Based on the standard deviations obtained for the various curve fits, it appears that the thickness of each layer can be measured to a precision of better than the required 3 percent, and the resistivity of each conducting layer can be measured to a precision of better than the required 10 percent using the frequencies and the probe described above. 


\begin{tabular}{|c|c|c|c|c|}
\hline Sir. Set & ies & $\begin{array}{c}\text { La's Th, } \\
\text {, }\end{array}$ & $\begin{array}{l}\text { Resist } \\
\text { Moct }\end{array}$ & $\begin{array}{l}f \in i . \\
\text { fia. }\end{array}$ \\
\hline \multirow[t]{5}{*}{$i$} & $\vdots$ & $1.2700 E+60$ & S. SAE+ & $\therefore .60$ \\
\hline & 2 & $2.0320 E-10$ & $\therefore a t+a$ & $\therefore .60$ \\
\hline & 3 & $i .060$ aE- $-\mathrm{i}$ & $\therefore$ STE+3! & \\
\hline & 4 & $7.32005-a$ & :.065t+o & \\
\hline & 5 & $2.5605 \div 11$ & $1.00 E+10$ & 1.60 \\
\hline \multirow[t]{5}{*}{2} & 1 & $\therefore .2700 E-00$ & $5.24 E+00$ & 1.08 \\
\hline & 2 & $2.03200-10$ & 1. COEE +10 & 1,00 \\
\hline & $?$ & $1.1430 E-0 i$ & $2.00 E+00$ & 1.00 \\
\hline & 4 & $7.3200 E-102$ & $1.00 E \div: 0$ & $\therefore .00$ \\
\hline & 5 & $\therefore .54005+11$ & $\therefore .00 E+10$ & 1.00 \\
\hline \multirow[t]{5}{*}{$\because$} & 1 & $1.97008+00$ & $5.24 E+00$ & 1.00 \\
\hline & 2 & $2.03 \div 0 E-10$ & $\therefore .005+10$ & 1.00 \\
\hline & 3 & $\therefore \quad \therefore 192 E-01$ & $2.5 i E+00$ & $\therefore .00$ \\
\hline & 4 & $7.6200 E-02$ & $1.00 E \div 10$ & 1.00 \\
\hline & 5 & $2.5400 E+11$ & 1.00E+1: & 1.00 \\
\hline \multirow[t]{5}{*}{4} & $\mathbf{i}$ & $1.2700 E+00$ & $5.2+E+00$ & 1.00 \\
\hline & 2 & $2.0320 E-10$ & 1. $60 E \div 10$ & $\therefore 60$ \\
\hline & 3 & $1.0653 E-01$ & $2.50 E+60$ & 1.00 \\
\hline & 4 & 5. $1200 \mathrm{E}-02$ & 1.OCE+iO & $\therefore 60$ \\
\hline & 5 & $2.54005+11$ & $1.00 E+10$ & 1.00 \\
\hline \multirow[t]{5}{*}{$\because$} & $i$ & $1.2700 E+00$ & $5.24 E+10$ & 1.00 \\
\hline & 2 & $2.030 \mathrm{O}-10$ & 1. $00 E \div 10$ & 1.00 \\
\hline & 3 & $1.14 j 0 E-0) !$ & $2.575+00$ & 1.00 \\
\hline & 4 & $8.1200 E-02$ & $\therefore .00 E+10$ & 1.00 \\
\hline & 5 & $2.5400 E+1$ & $1.00 E+10$ & 1.00 \\
\hline \multirow[t]{5}{*}{ ó } & 1 & $\$ .27 C 0 E+00$ & $5.24 E+00$ & 1.00 \\
\hline & 2 & $2.0320 \mathrm{E}-10$ & $1.00 E+10$ & 1.00 \\
\hline & 3 & $1.2192 E-01$ & $2.00 E+0 \hat{0}$ & 1.00 \\
\hline & 4 & $9.1200 E-02$ & 1.00E+10 & 1.00 \\
\hline & 5 & $2.5400 E+11$ & $\pm .00 E+10$ & 1.00 \\
\hline \multirow[t]{5}{*}{7} & 1 & $1.2700 E+00$ & $5.24 E+00$ & 1.00 \\
\hline & 2 & $2.1590 E-01$ & 1.00E+10 & $\therefore .00$ \\
\hline & 3 & 1.0668E-01 & $2.57 E+00$ & 1.00 \\
\hline & 4 & $7.6200 E-02$ & $1.00 E+10$ & 1.00 \\
\hline & 5 & $2.5400 E+11$ & 1. $00 E+10$ & $\therefore .00$ \\
\hline \multirow[t]{5}{*}{8} & 1 & $\therefore .27005+00$ & $5.24 E+00$ & 1.00 \\
\hline & 2 & $2.1550 E-01$ & $\therefore .00 E+10$ & 1.00 \\
\hline & 3 & $1+14305-01$ & $2.60 E+00$ & $\therefore .00$ \\
\hline & 4 & $7.6200 E-02$ & $1.00 E+10$ & 1.00 \\
\hline & 5 & $2.5400 E+11$ & $1.005+10$ & 1.00 \\
\hline \multirow[t]{5}{*}{4} & 1 & i. $2700 E+00$ & $5.24 E+00$ & 1.00 \\
\hline & 2 & $2.1590 E-01$ & $1.00 E+10$ & 1.00 \\
\hline & 3 & $1.2192 \varepsilon-01$ & $2.575+00$ & 1.00 \\
\hline & 4 & $7.6200 E-02$ & $1.00 E+10$ & 1.00 \\
\hline & 5 & $2.54000+11$ & $1.00 E+10$ & 1.00 \\
\hline
\end{tabular}

Figure 4. Twenty-Four Property Sets for the Five-Layer System 


\begin{tabular}{|c|c|c|c|c|}
\hline \multirow[t]{5}{*}{10} & 1 & $\therefore .2700 E+01$ & $5.24 E+00$ & $1.00^{\prime}$ \\
\hline & 2 & $2.1590 \mathrm{E}-01$ & $1.00 E+10$ & 1.00 \\
\hline & 3 & 1.1660E-01 & 2. $60 E+00$ & 1.00 \\
\hline & 4 & $9.1200 E-02$ & $1.00 E+10$ & 1.00 \\
\hline & 5 & $2.5400 E+11$ & $1+00 E+10$ & 1.00 \\
\hline \multirow[t]{5}{*}{ !! } & $\vdots$ & $1.2700 E+00$ & $5.24 E+00$ & 1.00 \\
\hline & 2 & $2.1590 E-01$ & $1.00 E+10$ & 1.00 \\
\hline & 3 & $i+1430 E-01$ & $2.57 E+C O$ & $\therefore .00$ \\
\hline & 4 & $8.12005-0 z$ & $1.00 E+10$ & $\therefore .00$ \\
\hline & 5 & $-5+20 E+11$ & $1, C O E+10$ & 1.00 \\
\hline \multirow[t]{5}{*}{12} & 1 & $1 . \overline{2700 E+00}$ & $5.24 E+00$ & 1.00 \\
\hline & 2 & $\therefore+1590 E-0 !$ & $1.005 \div 10$ & 2.00 \\
\hline & 3 & $1.2392 E-01$ & $2.60 E+00$ & $i .60$ \\
\hline & 4 & $3.1200 E-72$ & $1.00 E+10$ & 1.00 \\
\hline & 5 & $2.5400 E+1 !$ & $1.00 E+10$ & 1.00 \\
\hline \multirow[t]{5}{*}{$\therefore 3$} & 1 & $1.2700 E+00$ & $5.24 E+0 C$ & 1.00 \\
\hline & 2 & $2.0320 E-01$ & $1.00 E \div 10$ & 1.00 \\
\hline & $?$ & $1.0658 E-0 \mathrm{i}$ & $2.57 E+00$ & 1.00 \\
\hline & 4 & $7.6200 E-02$ & i. $00 E+1 \mathrm{v}$ & 2.00 \\
\hline & 5 & $2.5400 E+11$ & 1.00E+10 & 1.60 \\
\hline \multirow[t]{5}{*}{$i A$} & 1 & $1,2700 \mathrm{NE}+00$ & $3.24 E+00$ & $\therefore .00$ \\
\hline & 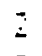 & $2+C 320 E-01$ & $1.00 E+10$ & 1.00 \\
\hline & 7 & $2.2430 E-1) 1$ & $2.60 E+00$ & 1.00 \\
\hline & $\dot{5}$ & $? .6200 \mathrm{E}-02$ & $\therefore .00 E+10$ & 1.00 \\
\hline & $\bar{z}$ & $2.5400 E+11$ & $1.00 E+10$ & 1.00 \\
\hline \multirow[t]{5}{*}{15} & 1 & $1.2700 \mathrm{EE}+06$ & $\Xi 24 E+00$ & 1.00 \\
\hline & $\therefore$ & $2.0720 E-01$ & 1.OCE +10 & 1.00 \\
\hline & $\ddot{z}$ & $\left(22^{5} 2 E-01\right.$ & $2.57 E+\infty 0$ & $\therefore, 00$ \\
\hline & 4 & $7.62005-02$ & $1.00 E+10$ & 1.00 \\
\hline & 5 & $2.5400 \varepsilon+11$ & 1.00E+10 & 1.00 \\
\hline \multirow[t]{5}{*}{ : } & 1 & $1.3700 E+00$ & $5.24 E+00$ & 1.00 \\
\hline & 2 & $2.03 \div 5-01$ & 1.00E+10 & 1.00 \\
\hline & 3 & $1.0668 E-01$ & $2.60 E+00$ & 1.00 \\
\hline & 4 & $3.1200 E-02$ & $1.00 E+10$ & $\therefore .00$ \\
\hline & 5 & $2.5 \neq 00 E+11$ & $1.00 E+10$ & 1.00 \\
\hline \multirow[t]{5}{*}{17} & $:$ & $\therefore .2700 E+00$ & $5.24 E+00$ & 1.00 \\
\hline & 2 & $2.0320 E-01$ & $1.00 E+10$ & 1.00 \\
\hline & 3 & $1.1430 E-0 !$ & $2.57 E+C O$ & 1.00 \\
\hline & 4 & $8.1200 E-02$ & $1.00 E+10$ & 1.00 \\
\hline & 5 & $2.5400 \varepsilon+11$ & $1.005+10$ & 1.00 \\
\hline \multirow[t]{5}{*}{15} & 1 & $1.37005+00$ & $5.24 E+00$ & 2.00 \\
\hline & 2 & $2,03 \mathrm{~s} 0 \mathrm{E}-0 \mathrm{~L}$ & $1.00 E+10$ & 1.00 \\
\hline & 3 & $1.21 \bar{Y} ? E-01$ & $2.005 \div 00$ & 1.00 \\
\hline & 4 & $0.1200 E-02$ & $1.005+10$ & $\therefore, 00$ \\
\hline & $\Xi$ & $2.5400 E+11$ & $1.00 E+10$ & 1.00 \\
\hline
\end{tabular}

Figure 4 Continued. Twenty-Four Property Sets for the Five-Layer System 


\begin{tabular}{|c|c|c|c|c|}
\hline \multirow[t]{5}{*}{9} & $!$ & $1.2700 E+00$ & $3.24 E+00^{\circ}$ & 1.00 \\
\hline & 2 & $2.1550 E-0 !$ & $\therefore .00 E+10$ & 1.00 \\
\hline & 3 & 1.0638E-j)! & $2.57 E \div 00$ & $\therefore .00$ \\
\hline & 4 & $7.6200 E-02$ & $1.00 E+10$ & 1.00 \\
\hline & 5 & $2.5400 E+11$ & 1. OOE 10 & 1.00 \\
\hline \multirow[t]{5}{*}{20} & 1 & $1,2700 \mathrm{E} \div 00$ & $5.24 E+C 0$ & 1.00 \\
\hline & 2 & $2.1590 E-01$ & 1. COE +10 & 1.00 \\
\hline & 3 & $1.14305-01$ & $2.50 E+00$ & 1.00 \\
\hline & 4 & $\because .5200 E-02$ & $1.00 E+10$ & 1.00 \\
\hline & 5 & $2.5400 E+11$ & $1.005+10$ & 1.00 \\
\hline \multirow[t]{5}{*}{$a$} & 1 & $1.2700 E+00$ & $5.24 E+00$ & 1.00 \\
\hline & 2 & $3.1590 E-01$ & $1.00 E+10$ & 1.00 \\
\hline & 3 & 1.219:E-101 & $2.57 E+00$ & 5.00 \\
\hline & 4 & $7.6200 E-02$ & $1.00 E+10$ & 1.00 \\
\hline & $\Xi$ & 2.5400E+11 & $1.00 E+10$ & 1.00 \\
\hline \multirow[t]{5}{*}{22} & $i$ & $1.2700 E+00$ & $5.24 E+00$ & 1.00 \\
\hline & 2 & $2.1590 E-01$ & 1.00E+10 & 1.00 \\
\hline & 3 & $1.0668 \mathrm{E}-01$ & $2.60 E+00$ & 1.00 \\
\hline & 4 & $8.1200 E-02$ & $1.00 E+10$ & 1.00 \\
\hline & 5 & $2.5400 E+11$ & $1.00 E+10$ & 1.00 \\
\hline \multirow[t]{5}{*}{23} & 1 & $1.2700 E+100$ & $5.24 E+00$ & 1.00 \\
\hline & 2 & $2.1590 \mathrm{E}-01$ & $1.00 E+10$ & 1.00 \\
\hline & 3 & $1.1430 E-01$ & $2.57 E+00$ & 1.00 \\
\hline & 4 & $8.1200 E-02$ & 1. COET:O & 1.00 \\
\hline & 5 & $2.5400 E+11$ & $1.00 E+10$ & 1.00 \\
\hline \multirow[t]{5}{*}{24} & 1 & $1.2700 E+00$ & $5.24 E+00$ & $\therefore .00$ \\
\hline & 2 & $2.1590 E-01$ & $1.00 E+10$ & 1.00 \\
\hline & 3 & $1.2192 \mathrm{E}-01$ & $2.60 E+00$ & 1.00 \\
\hline & 4 & $8.1200 E-02$ & $1.00 E+10$ & 1.00 \\
\hline & 5 & $2.5400 E+11$ & $1.00 E+10$ & 1.00 \\
\hline
\end{tabular}

Figure 4 Continued. Twenty-Four Property Sets for the Five-Layer System

\section{ACCOMPLISHMENTS}

The MULFRD design program was applied to two laminar composites of interest. From this program it can be concluded that multifrequency eddy current techniques can be successfully used to measure the thickness and resistivity of the various layers of these composites to the required precisions. It was found that for the five-layered composite consisting of an aluminum substrate, a layer of Kapton insulator, a center physical vapor deposited aluminum conductor, and a top layer of Kapton, that either the 20-C or 40-A probe operated at frequencies of $200 \mathrm{kHz}$ and $1 \mathrm{MHz}$ produced acceptable results within the required tolerance. In the case of the six-layered composite consisting of an aluminum substrate, a polyimide insulator layer, a layer of physical vapor 


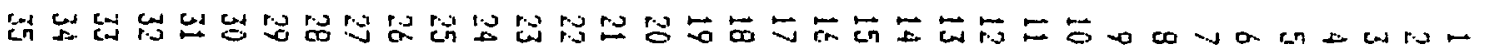

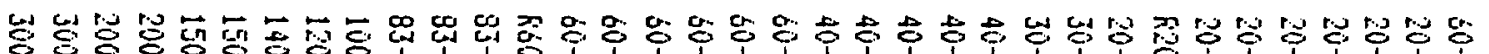

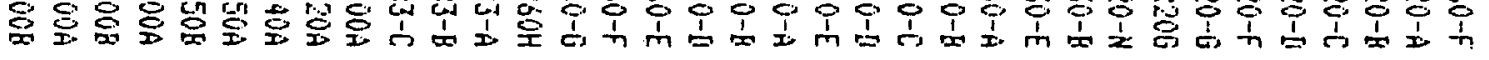
00000009000000000000000000000000000

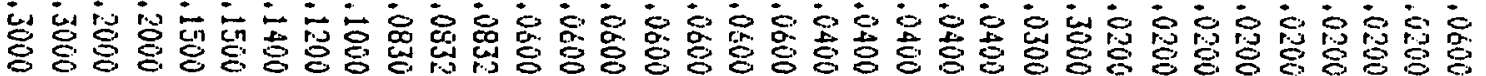

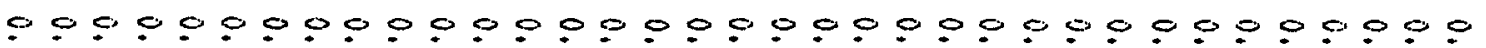

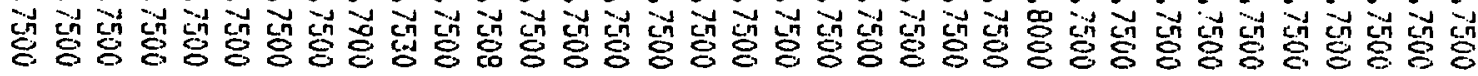
F十 -

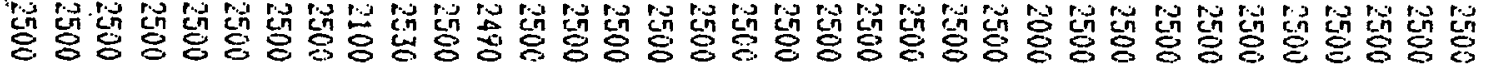

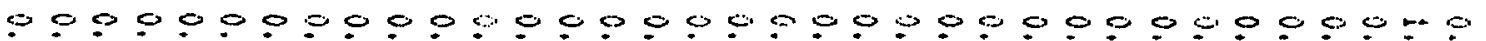

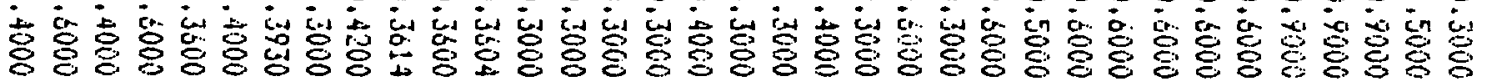
$00000000000005000000500000000005 \% 90$

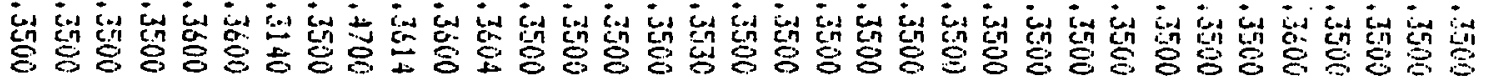

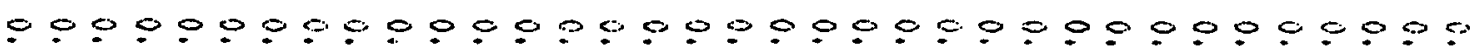

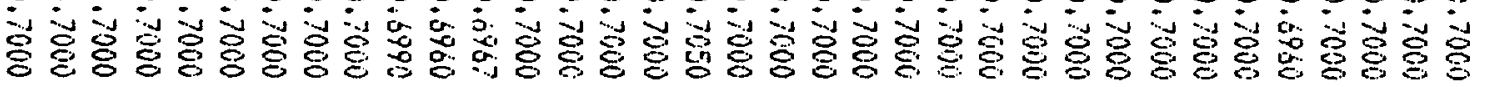

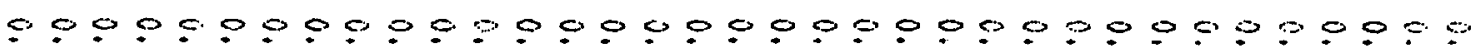

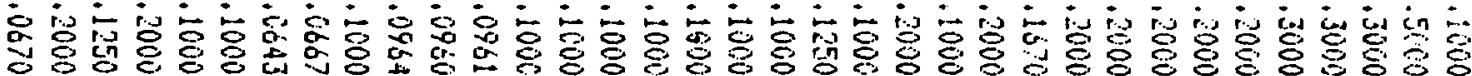
O

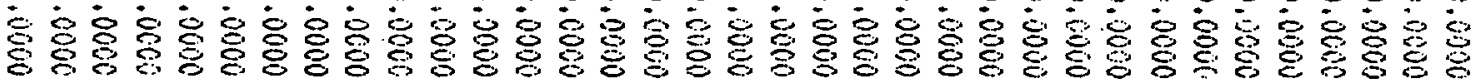
О.

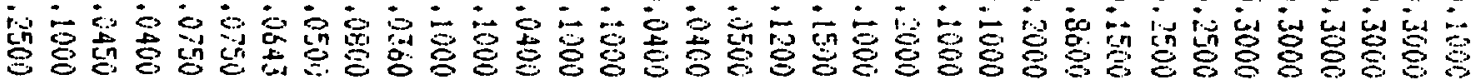

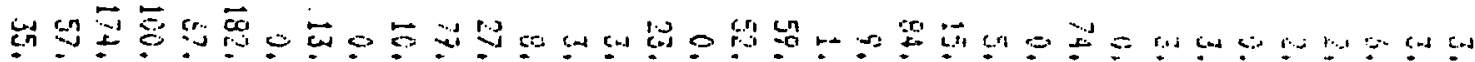
吾留 8

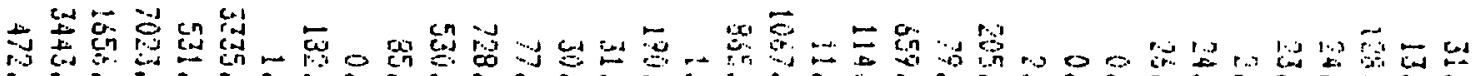

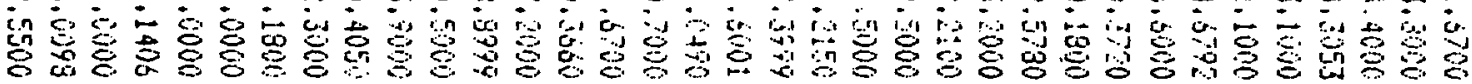

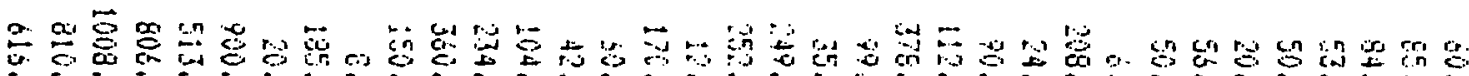

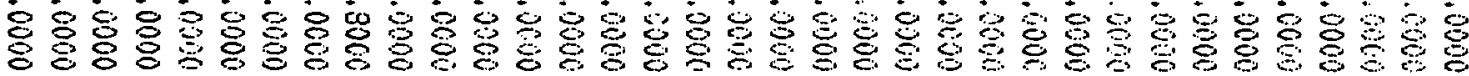

2

5

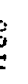

吝

$=$

.

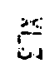

is

事

3

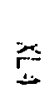

?a

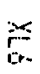

涪

है

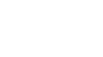

鹃

2

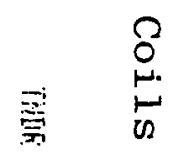

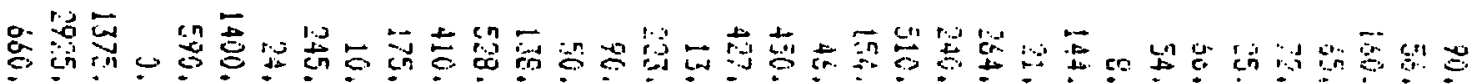

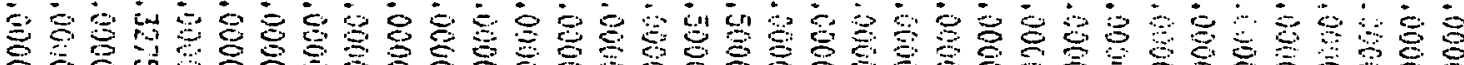


Table 4 Continue

\begin{tabular}{|c|c|c|c|c|c|c|c|c|c|c|c|c|c|}
\hline $400 \mathrm{~A}$ & 0.4000 & 0.7500 & 1.250 & 1900 & 0.3500 & 0.7000 & 0.2000 & 0.0000 & 0.0400 & 3.2378 & 99.0500 & 238.0000 & $35 \overline{8} .0000$ \\
\hline 4006 & 0.4000 & 0.7500 & 1.2500 & 、 & 0.3500 & 0.7000 & 0.2000 & 0.0000 & 0.0125 & 3.4130 & 190.3800 & 238.0000 & 1000 \\
\hline $400 \mathrm{C}$ & 0.4000 & 0.7500 & 1.2500 & 0.4 & 1.3500 & 0.7000 & 0.0550 & 0.0000 & 0.0400 & 13.0070 & 161.2700 & 414.0000 & \\
\hline $183 \mathrm{~B}$ & 0.1830 & 0.9613 & 1.0582 & 0.382 & .450 & 0.9180 & 0.1530 & 0.0000 & & & & 16.0600 & 73.0000 \\
\hline & .0000 & 0.0000 & 0.0000 & 0.00000 & 1 & 0.00000 & 0.0000 & 0.0000 & 0.0000 & 0.0000 & 0.0000 & 0.0000 & 0.0000 \\
\hline
\end{tabular}


Definition of Headings in Table 4

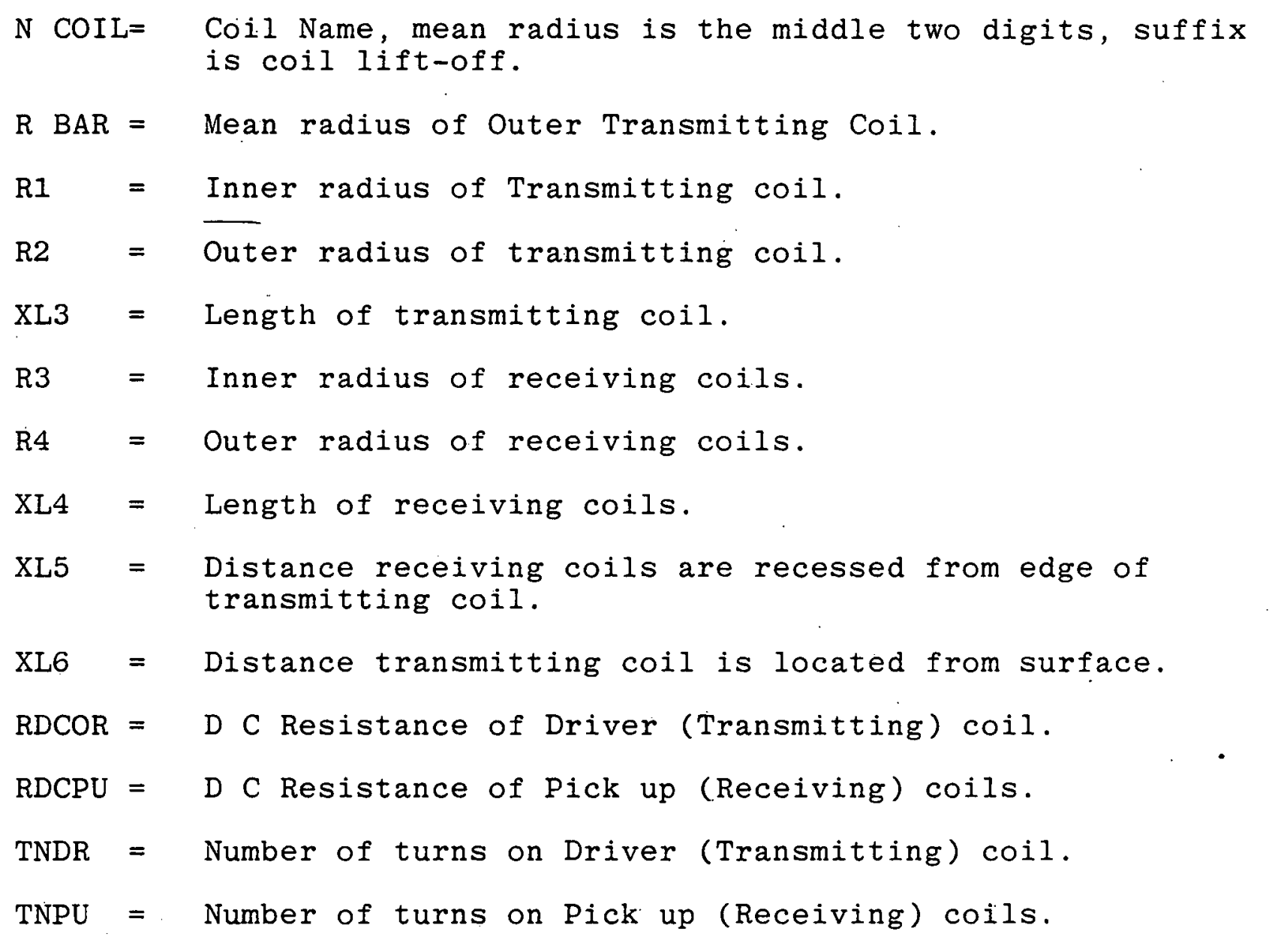

deposited aluminum, a layer of polyimide insulator, and an outer layer of physical vapor deposited aluminum, two frequencies did not completely define the problem so that three frequencies were required. For this composite it was found that a 20-C probe operated at 100 and $200 \mathrm{kHz}$ and $1 \mathrm{MHz}$ could adequately measure the thickness and resistivity of the individual layers. The 40-A probe also was adequate but in certain instances the drift component was slightly larger. Although it remains to verify these findings with actual experimental measurements it would appear that both of these composites can be successfully measured using this technique.

\section{FUTURE WORK}

The two and three frequency systems simulated in this study are now being assembled. The two frequency hardware has all been 
Table 5. Summary of Five-Layer Calculations Using 20-C and 40-A Probes

A. Summary of Calculation with 20-C Probe and 40-A Probe

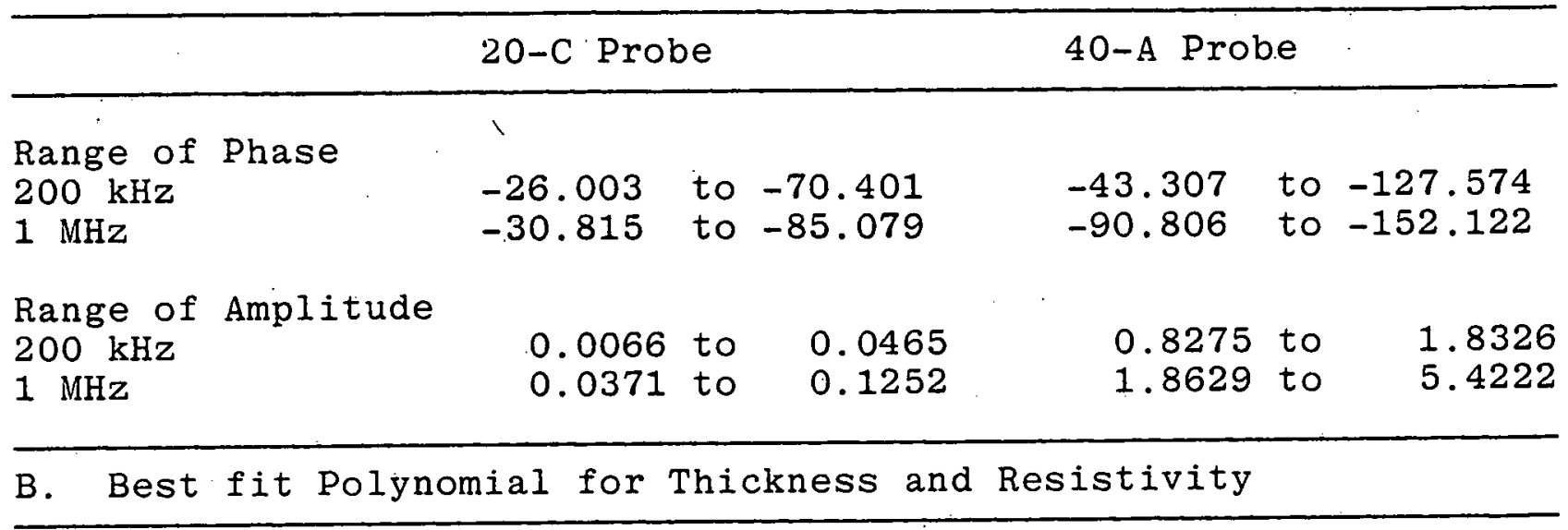

NOTE: The format of the polynomial is (function), (power), (number of crossterms).

For the function $1=$ Linear, $2=\log , 3=\operatorname{Exp}$, and $4=\operatorname{Inv}$. i.e. $1,2,0$ is Linear, Second Order, No Crossterms

$\begin{array}{lll}\text { Layer 2, Thickness } & & \\ \text { Magnitude at } 200 \mathrm{kHz} & 3,2,0 & 2,2,0 \\ \text { Phase at 200 } \mathrm{kHz} & 1,2,1 & 1,2,0 \\ \text { Magnitude at } 1 \mathrm{MHz} & 2,2,0 & 2,2,0 \\ \text { Phase at } 1 \mathrm{MHz} & 1,2,0 & 1,2,0 \\ \text { Layer 3, Thickness } & & \\ \text { Magnitude at 200 kHz } & 2,2,0 & 1,2,0 \\ \text { Phase at 200 kHz } & 1,2,0 & 1,2,0 \\ \text { Magnitude at } 1 \mathrm{MHz} & 2,2,0 & 1,2,0 \\ \text { Phase at } 1 \mathrm{MHz} & 1,2,0 & 1,2,0 \\ \text { Layer 4, Thickness } & & \\ \text { Magnitude at 200 kHz } & 2,2,0 & 2,2,0 \\ \text { Phase at 200 kHz } & 1,2,0 & 1,2,0 \\ \text { Magnitude at } 1 \mathrm{MHz} & 2,2,0 & 2,2,0 \\ \text { Phase at } 1 \mathrm{MHz} & 1,2,0 & 1,2,0 \\ \text { Layer 3, Resistivity } & & \\ \text { Magnitude at } 200 \mathrm{kHz} & 2,2,0 & 2,2,0 \\ \text { Phase at 200 kHz } & 1,2,0 & 1,2,0 \\ \text { Magnitude at } 1 \mathrm{MHz} & 2,2,0 & 2,2,0 \\ \text { Phase at } 1 \mathrm{MHz} & 1,2,0 & 1,3,0\end{array}$


Table 5 Continued. Summary of Five-Layer Calculations Using 20-C and 40-A Probes

\begin{tabular}{lll}
\hline $\begin{array}{l}\text { Best Fit Thickness } \\
\text { Difference }\end{array}$ & $(\mathrm{mm})$ & $(\mathrm{mm})$ \\
\hline & & \\
Layer 2 & 0.00545 & 0.00539 \\
Layer 3 & 0.00049 & 0.00261 \\
Layer 4 & 0.00079 & 0.00193
\end{tabular}

Best Fit Resistivity

Difference $(\mu \Omega \cdot \mathrm{cm}) \quad(\mu \Omega \cdot \mathrm{cm})$

$\begin{array}{lll}\text { Layer } 3 & 0.02294 & 0.01381\end{array}$

Best Fit Drift

Thickness $(\mathrm{mm}) \quad(\mathrm{mm})$

\begin{tabular}{llll}
\hline Layer 2 & 0.00002 & 0.00002 \\
Layer 3 & 0.00001 & 0.00001 \\
Layer 4 & 0.00002 & 0.00001
\end{tabular}

\begin{tabular}{lll}
$\begin{array}{l}\text { Best Fit Drift } \\
\text { Resistivity }\end{array}$ & $(\mu \Omega \cdot \mathrm{cm})$ & $(\mu \Omega \cdot \mathrm{cm})$ \\
\hline Layer 3 & 0.00053 & 0.00024
\end{tabular}

built and the A/D for the NDT COMP 8 is the only major component which has not been made fully operational. A three frequency oscillator, and an additional phase detector module are now being assembled along with a computer controlled calibration module. These components are scheduled for completion in early February, 1980. With this hardware actual test samples of the two composites will be measured using the probes and instrument settings obtained in this report. The program used for this operation is RFLRDG, which has not yet been completely edited for use on the PDP 11/34 system. The results from these experimental readings will be analyzed using a program called RFLFIT. This program must also be edited.

Two additional flat laminates have been submitted for analysis. One of these laminates is associated with the thin film concept while the other has been submitted by LLL. It is intended that a capability study of the type described above will be carried out on these two systems. 
Table 6. Property Values and Ranges Used for Modeling the Six-Layered Composite

\begin{tabular}{llll}
\hline Layer & $\begin{array}{l}\text { Thickness } \\
(\mathrm{cm})\end{array}$ & $\begin{array}{l}\text { Resistivity } \\
(\mu \Omega \cdot \mathrm{cm})\end{array}$ & Permeability \\
\hline 1 & 0.01524 & 5.24 & 1 \\
2 & 0.0035 & $1 \times 10 \mathrm{E}(10)$ & 1 \\
& 0.0039 & $1 \times 10 \mathrm{E}(10)$ & 1 \\
3 & 0.0023 & 2.57 & 1 \\
& 0.0023 & 2.60 & 1 \\
& 0.0027 & 2.57 & 1 \\
4 & 0.0027 & 2.60 & 1 \\
& 0.0035 & $1 \times 10 \mathrm{E}(10)$ & 1 \\
5 & 0.0039 & $1 \times 10 \mathrm{E}(10)$ & 1 \\
& 0.0023 & 2.57 & 1 \\
& 0.0023 & 2.60 & 1 \\
& 0.0027 & 2.57 & 1 \\
& 0.0023 & 2.60 & 1 \\
& $1 \times 10 \mathrm{E}(10)$ & $1 \times 10 \mathrm{E}(10)$ & 1 \\
\hline
\end{tabular}


Table 7. Comparison of 20-C and 40-A Probes

A. Summary of Calculations with 20-C and 40-A Probe

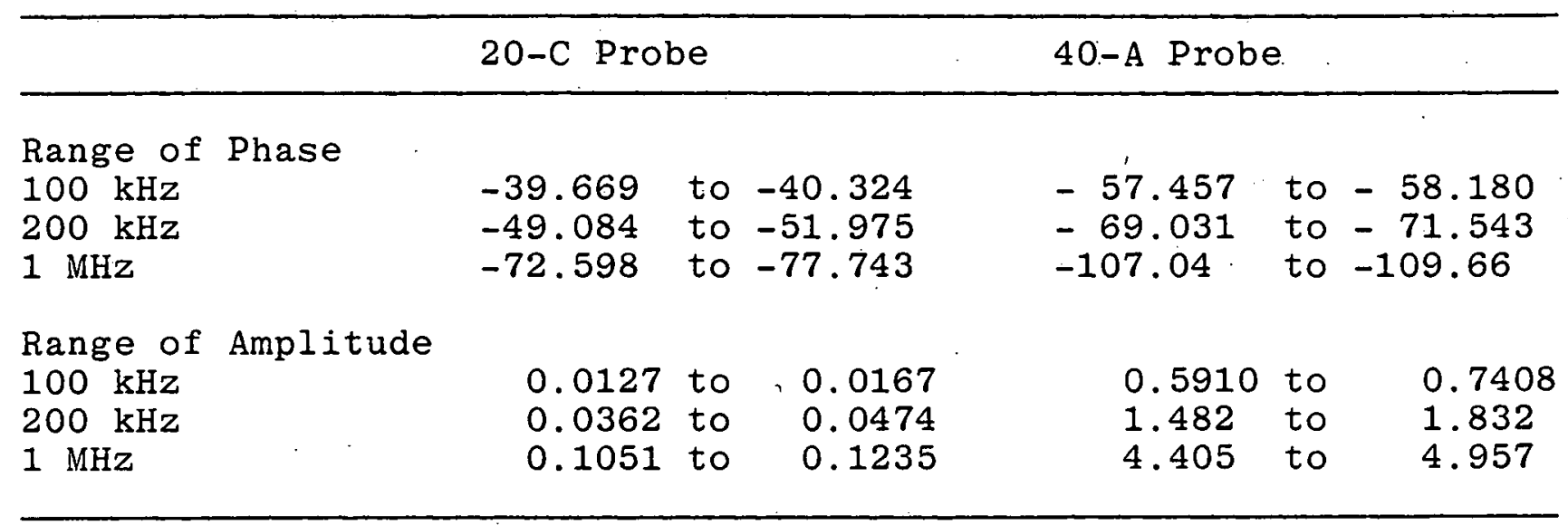

B. Best Fit Polynomial for Thickness and Resistivity

NOTE: The format of the polynomial is (function), (power), (number of crossterms).

For the function $1=$ Linear, $2=\log , 3=\operatorname{Exp}$, and $4=\operatorname{Inv}$. i.e. $1,2,0$ is Linear, Second Order, No Crossterms.

Layer 2, Thickness Magnitude at 100 Phase at $100 \mathrm{kHz}$ Magnitude at $200 \mathrm{kHz}$ Phase at $200 \mathrm{kHz}$ Magnitude at $1 \mathrm{MHz}$ Phase at $1 \mathrm{MHz}$

$\begin{array}{lll}\mathrm{kHz} & 1,2,0 & 2,2,0 \\ & 1,2,0 & 1,2,0 \\ \mathrm{kHz} & 1,2,0 & 2,2,0 \\ & 1,2,0 & 1,2,0 \\ \mathrm{kz} & 1,2,0 & 2,2,0 \\ & 1,2,0 & 1,2,0\end{array}$

Layer 3, Thickness

$\begin{array}{lll}\text { Magnitude at } 200 \mathrm{kHz} & 1,2,0 & 2,2,0 \\ \text { Phase at } 1.00 \mathrm{kHz} & 1,2,0 & 1,2,0 \\ \text { Magnitude at } 200 \mathrm{kHz} & 1,2,0 & 2,2,0 \\ \text { Phase at 200 } \mathrm{kHz} & 1,2,0 & 1,2,0 \\ \text { Magnitude at } 1 \mathrm{MHz} & 1,2,0 & 2,2,0 \\ \text { Phase at } 1 \mathrm{MHz} & 1,2,0 & 1,2,0\end{array}$

Layer 4., Thickness

$\begin{array}{lll}\text { Magnitude at } 100 \mathrm{kHz} & 2,2,1 & 2,2,0 \\ \text { Phase at } 100 \mathrm{kHz} & 1,2,0 & 1,2,0 \\ \text { Magnitude at } 200 \mathrm{kHz} & 2,2,1 & 2,2,0 \\ \text { Phase at 200 } \mathrm{kHz} & 1,2,0 & 1,2,0 \\ \text { Magnitude at } 1 \mathrm{MHz} & 2,2,1 & 2,2,0 \\ \text { Phase at } 1 \mathrm{MHz} & 1,2,0 & 1,2,0\end{array}$


Table 7 Continued. Comparison of 20-C and 40-A Probes

$\begin{array}{lll}\text { Layer } 5 \text {, Thickness } & & \\ \text { Magnitude at } 100 \mathrm{kHz} & 1,1,0 & 2,2,0 \\ \text { Phase at } 100 \mathrm{kHz} & 1,2,0 & 1,2,0 \\ \text { Magnitude at } 200 \mathrm{kHz} & 1,1,0 & 2,2,0 \\ \text { Phase at 200 } \mathrm{kHz} & 1,2,0 & 1,2,0 \\ \text { Magnitude at } 1 \mathrm{MHz} & 1,1,0 & 2,2,0 \\ \text { Phase at } 1 \mathrm{MHz} & 1,2,0 & 1,2,0 \\ & & \\ \text { Layer 3, Resistivity } & & \\ \text { Magnitude at } 100 \mathrm{kHz} & 1,2,0 & 1,2,0 \\ \text { Phase at 200 } \mathrm{kHz} & 1,2,0 & 1,2,0 \\ \text { Magnitude at } 200 \mathrm{kHz} & 1,2,0 & 1,2,0 \\ \text { Phase at 200 } \mathrm{kHz} & 1,2,0 & 1,2,0 \\ \text { Magnitude at } 1 \mathrm{MHz} & 1,2,0 & 1,2,0 \\ \text { Phase at 1 MHz } & 1,2,0 & 1,2,0 \\ \text { Layer 5, Resistivity } & & \\ \text { Magnitude at } 100 \mathrm{kHz} & 2,2,0 & 1,2,0 \\ \text { Phase at 100 kHz } & 1,2,0 & 1,2,0 \\ \text { Magnitude at } 200 \mathrm{kHz} & 2,2,0 & 1,2,0 \\ \text { Phase at 200 } \mathrm{kHz} & 1,2,0 & 1,2,0 \\ \text { Magnitude at } 1 \mathrm{MHz} & 2,2,0 & 1,2,0 \\ \text { Phase at } 1 \mathrm{MHz} & 1,2,0 & 1,2,0\end{array}$

Best Fit Thickness

Difference

$(\mathrm{mm}) \quad(\mathrm{mm})$

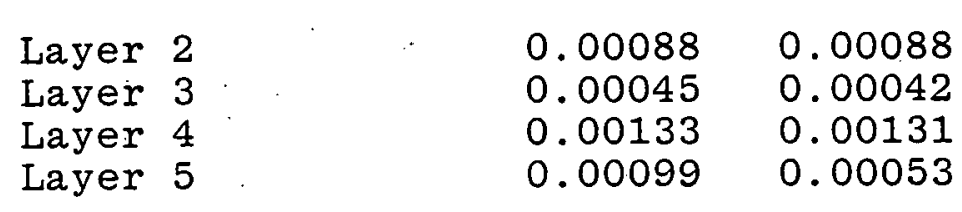

Best Fit Resistivity

Difference

$(\mu \Omega \cdot \mathrm{cm}) \quad(\mu \Omega \cdot \mathrm{cm})$

$\begin{array}{lll}\text { Layer } 3 & 0.01448 & 0.01455 \\ \text { Layer } 5 & 0.01487 & 0.01489\end{array}$

Best Fit Drift

Thickness (mm) (mm)

$\begin{array}{lll}\text { Layer } 2 & 0.0010 & 0.0023 \\ \text { Layer } 3 & 0.0012 & 0.0046 \\ \text { Layer } 4 & 0.0098 & 0.0089 \\ \text { Layer } 5 & 0.0007 & 0.0025\end{array}$


Table 7 Continued. Comparison of 20-C and 40-A Probes

\begin{tabular}{lll}
$\begin{array}{l}\text { Best Fit Drift } \\
\text { Resistivity }\end{array}$ & $(\mathrm{mm})$ & $(\mathrm{mm})$ \\
\hline Layer 3 & 0.0496 & 0.0570 \\
Layer 5 & 0.0137 & 0.0100
\end{tabular}




\section{REFERENCES}

${ }^{1}$ C. V. Dodd, and L. D. Chitwood, Three Frequency Eddy-Current Instrument For Multiple Property Problems, ORNL-5495, March 1979 .

${ }^{2}$ W. E. Deeds, C. V. Dodd, G. W. Scott, Computer-Aided Design of

- Multifrequency Eddy-Current Tests For Layered Conductors With Multiple Property Variations, ORNL/TM-6858, October, 1979.

${ }^{3}$ R. V. Heckman, Simultaneous Measurement of Multilayered Composites, BDX-613-2176, September, 1979 . 
Appendix A

LISTING FOR MULTILAYERED REFLECTION COIL DESIGN (MULFRD) 
$r^{1}-\cdots$

and

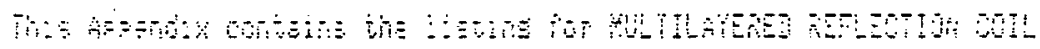

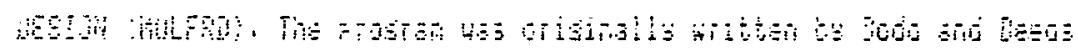

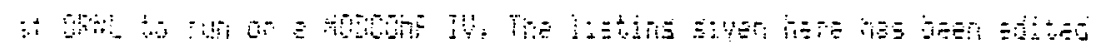
n-

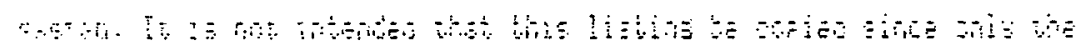

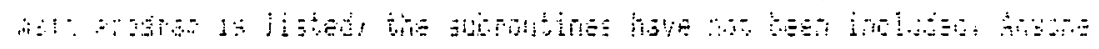

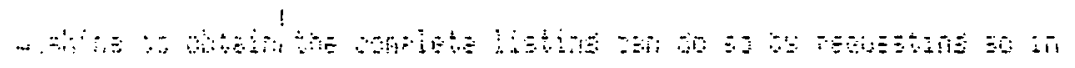

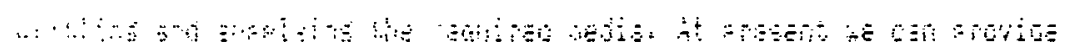
- : : 


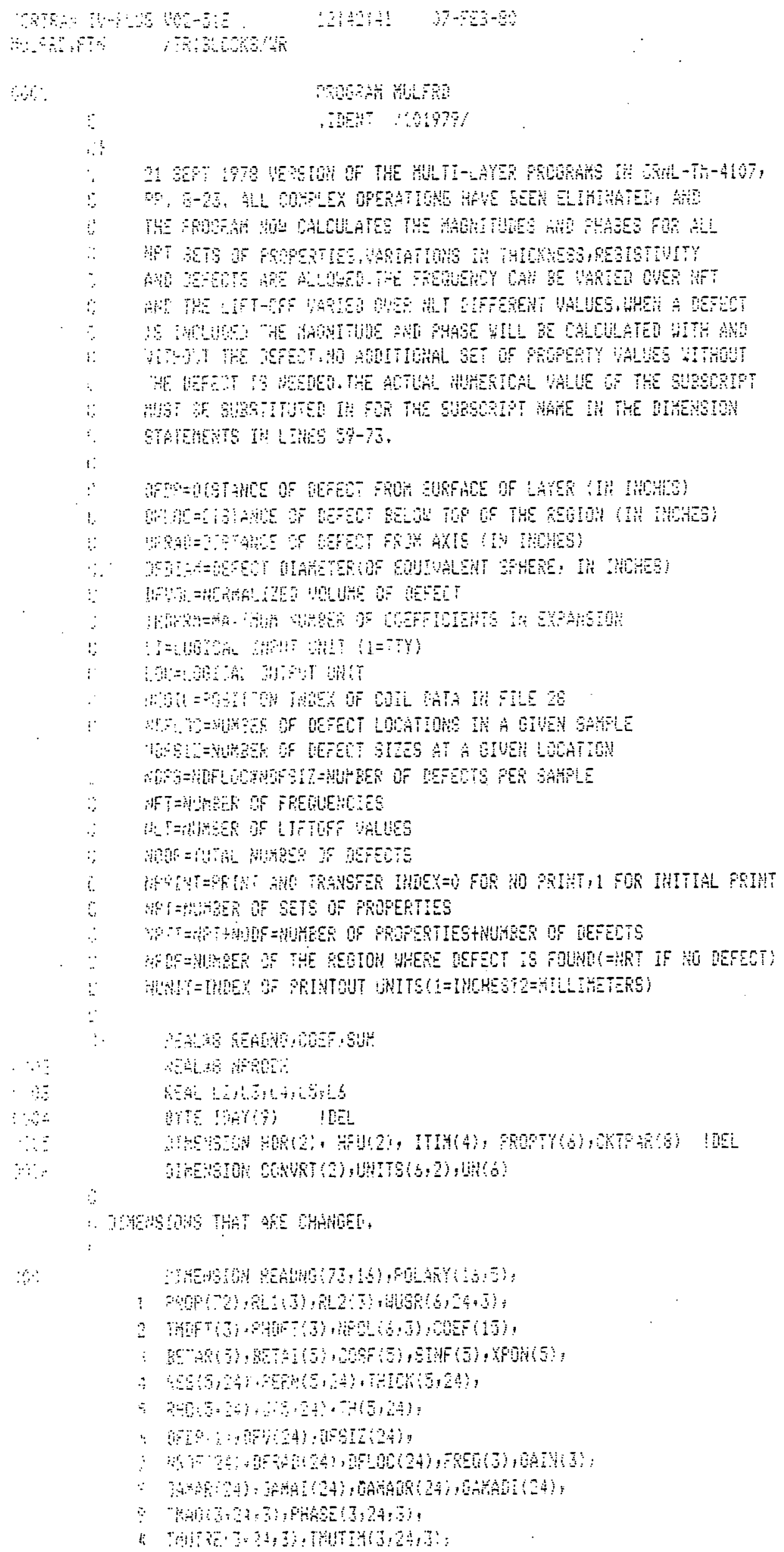




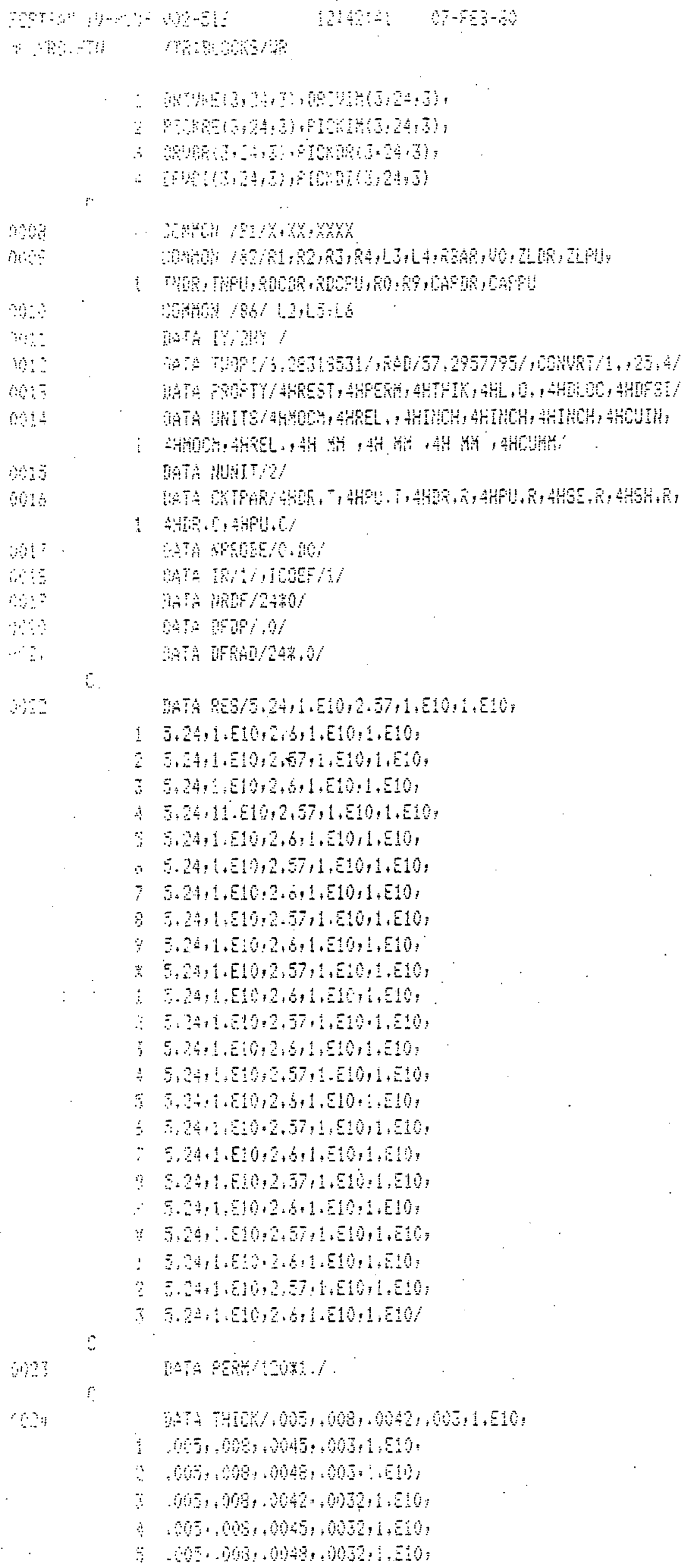




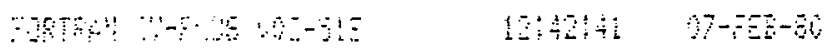

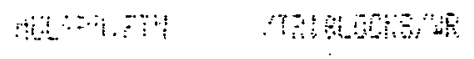

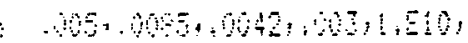

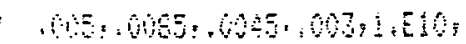

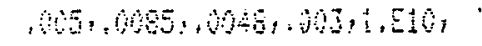

. $65,005,004,0032,1,510$

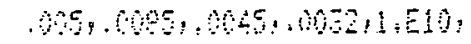

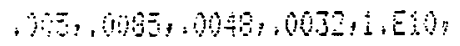

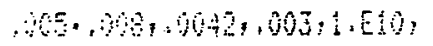

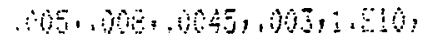

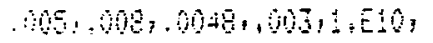

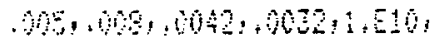

, $605,008,0945,0032,4510$

Ac

.06, ,0es, .004, 003:,$E 10$

$.65 ;, 005,0045,003,1, E 107$

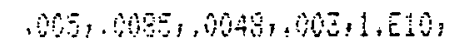

$.005,0005,0042,0032,1+20$

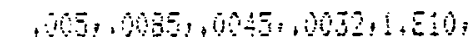

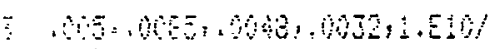

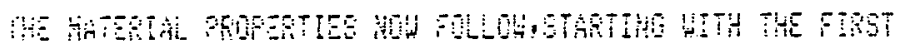

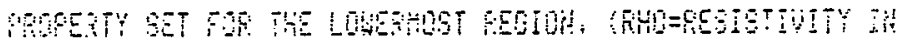

5 ATOHAG?

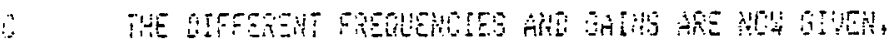

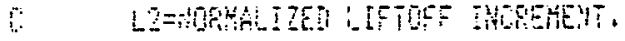

MO HA FREM

we

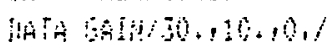

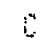

कin

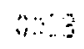

is

(3)

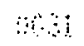

$\because$

and

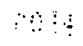

10

a:

$\dddot{n+3}$

35

itis

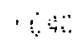

a in:

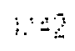

(6) 43

bi:4

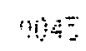

$3+5$

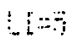

int:

AfFing $=$ ?

in $?=3$

$: T=2$

$T=5$

Af $T=24$

MRT:

पip $3 i \bar{z}=0$

nothing 0

$M T=1$

InFM=15

Mips:0

WF: $=1$

nim: $=0$

$47=24$

$50 \mathrm{i}=73$

$402=85$

$407=72$

34

$L 2=1935$

$\because$

14

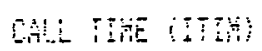

DAL IATE (IDAY)

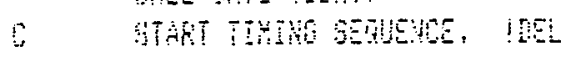

$0 ;$

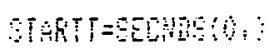

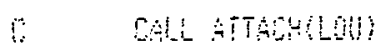

$m p$

Hก: this: 


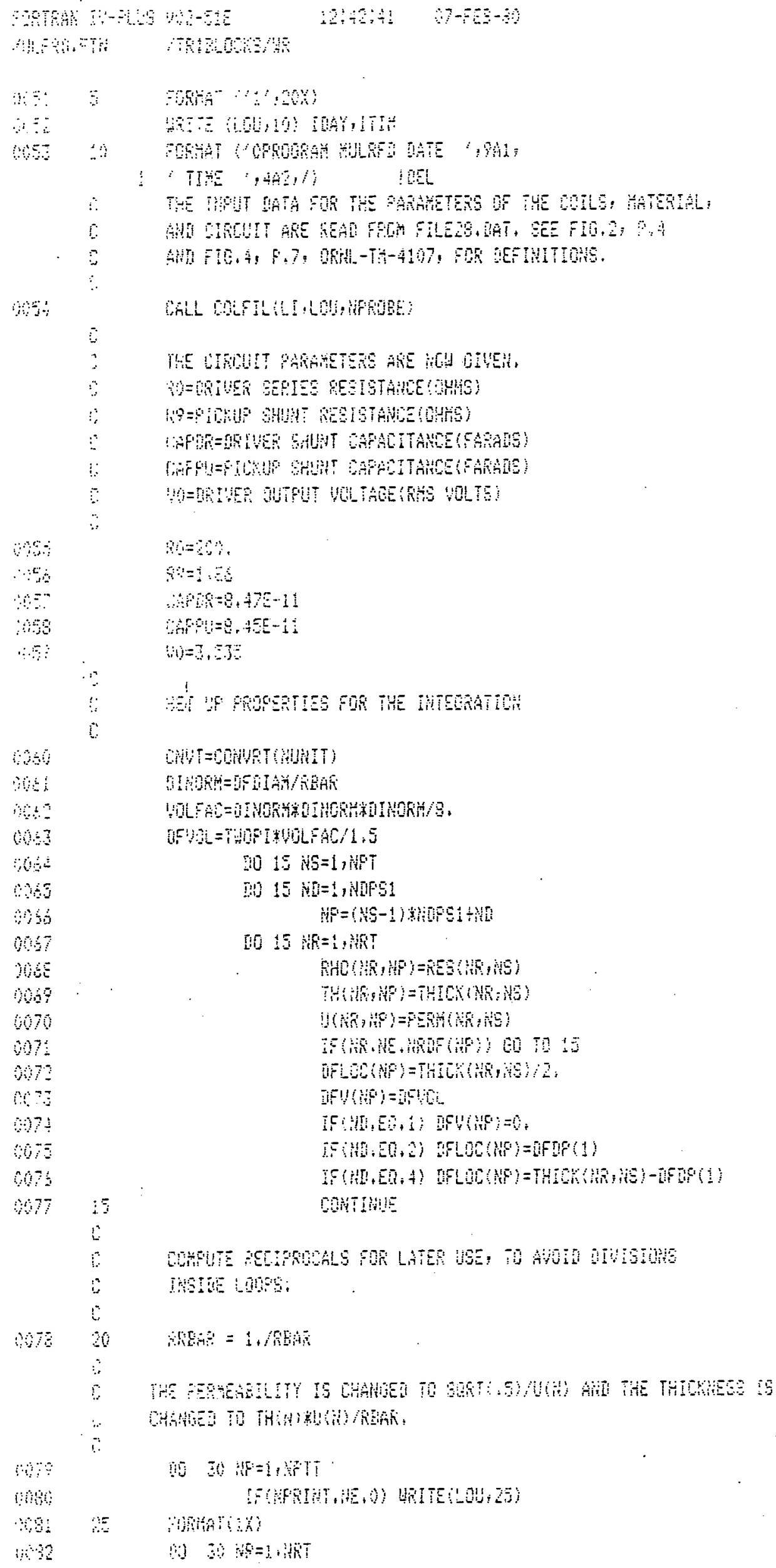




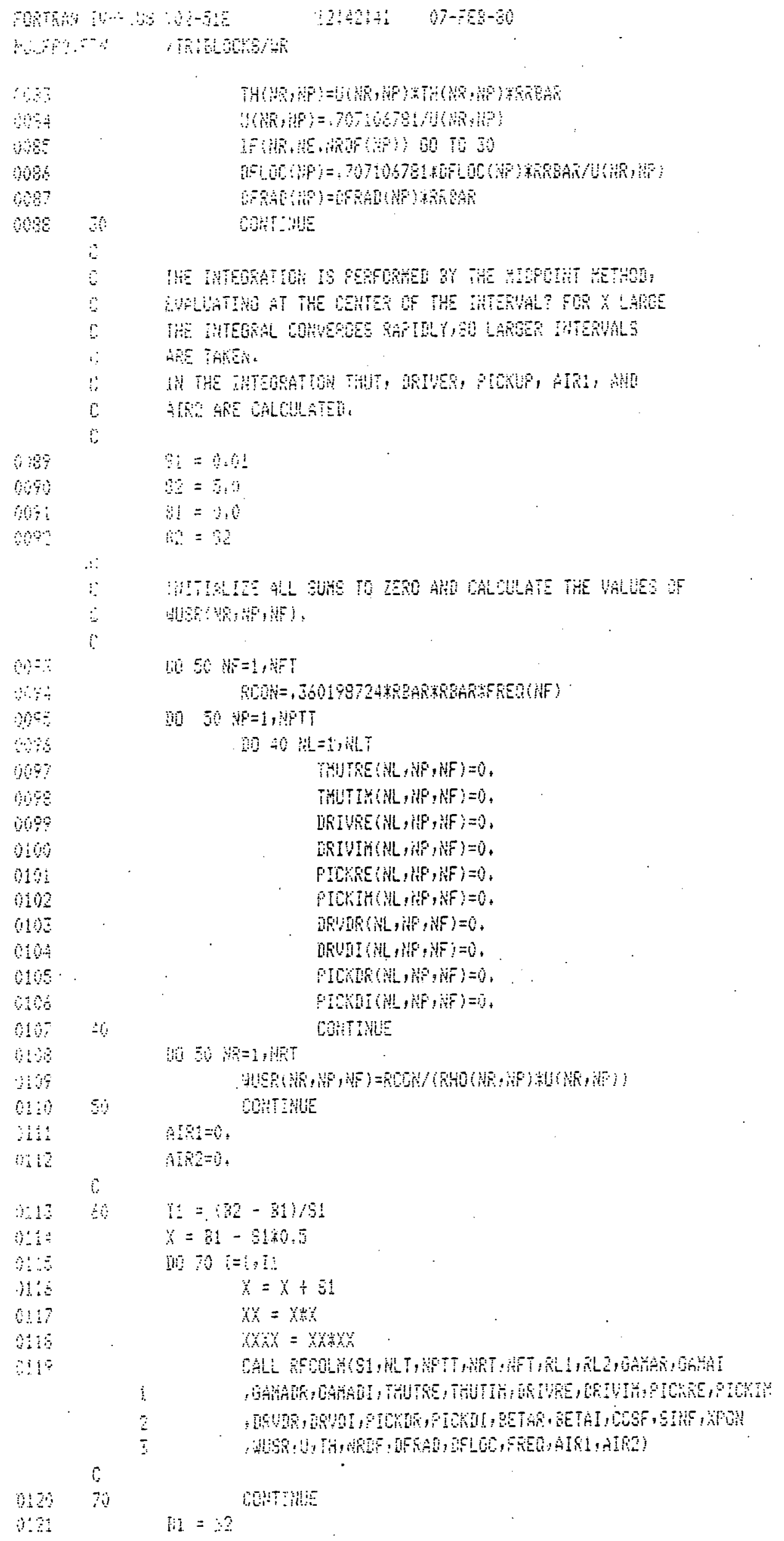




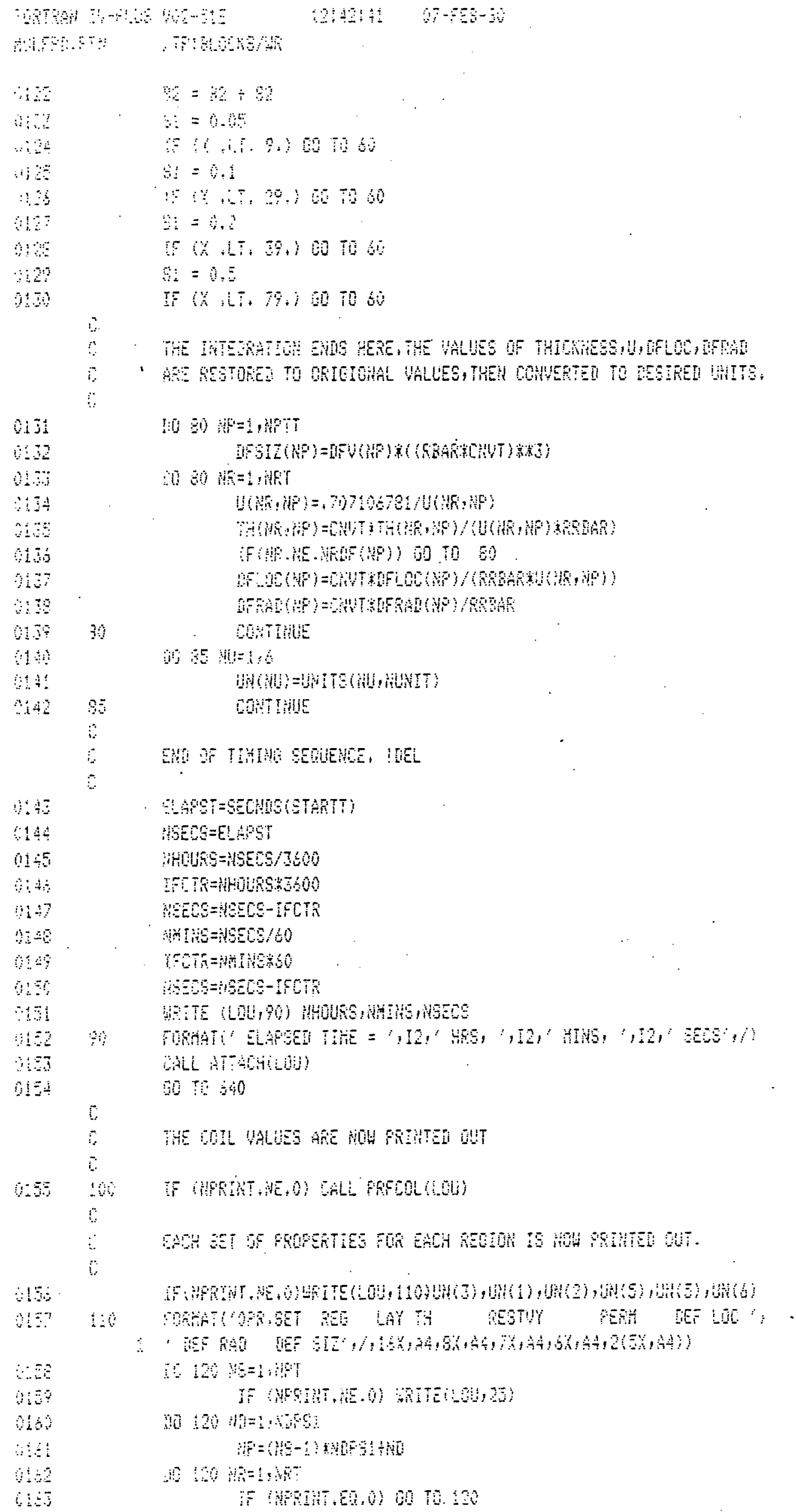




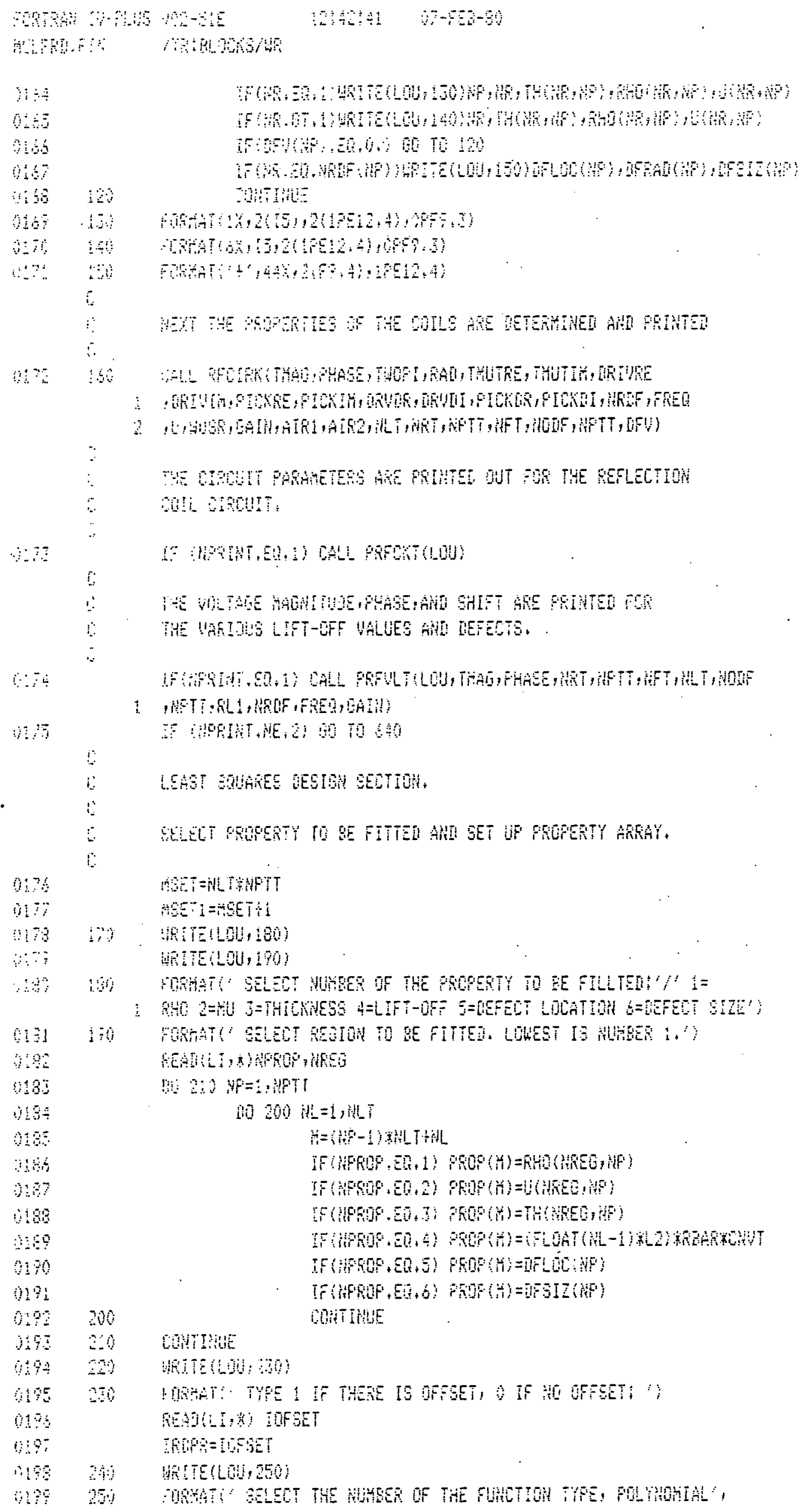




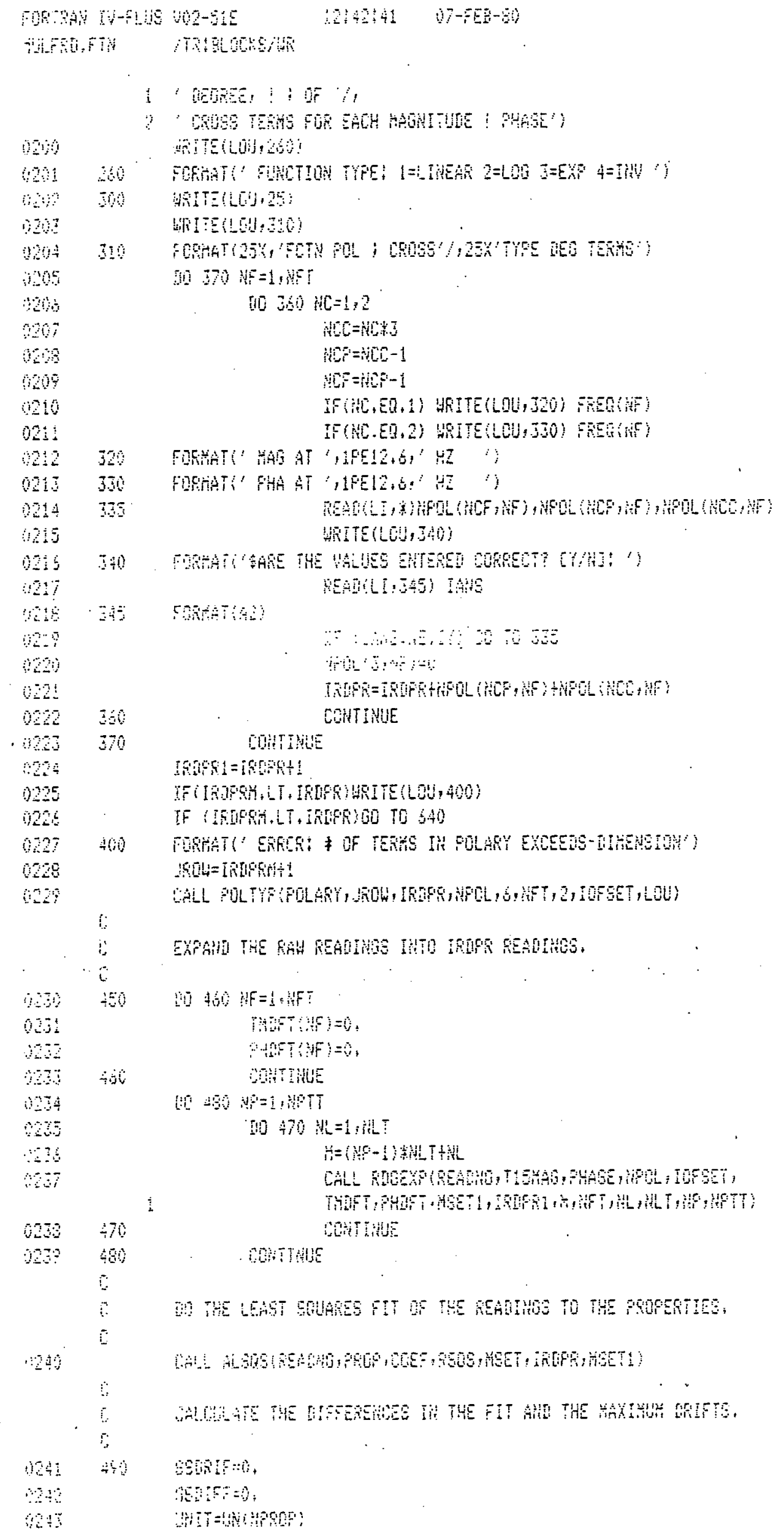




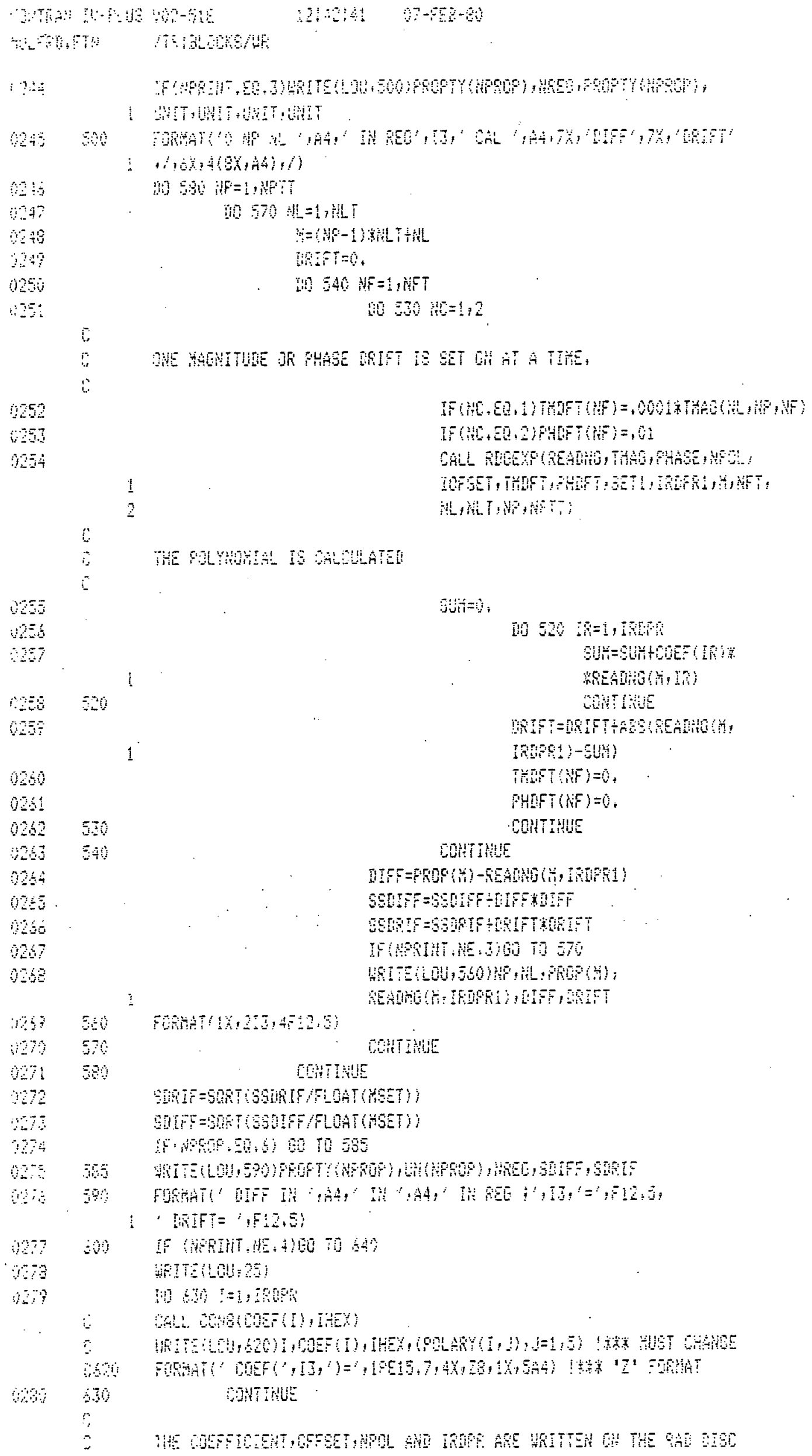




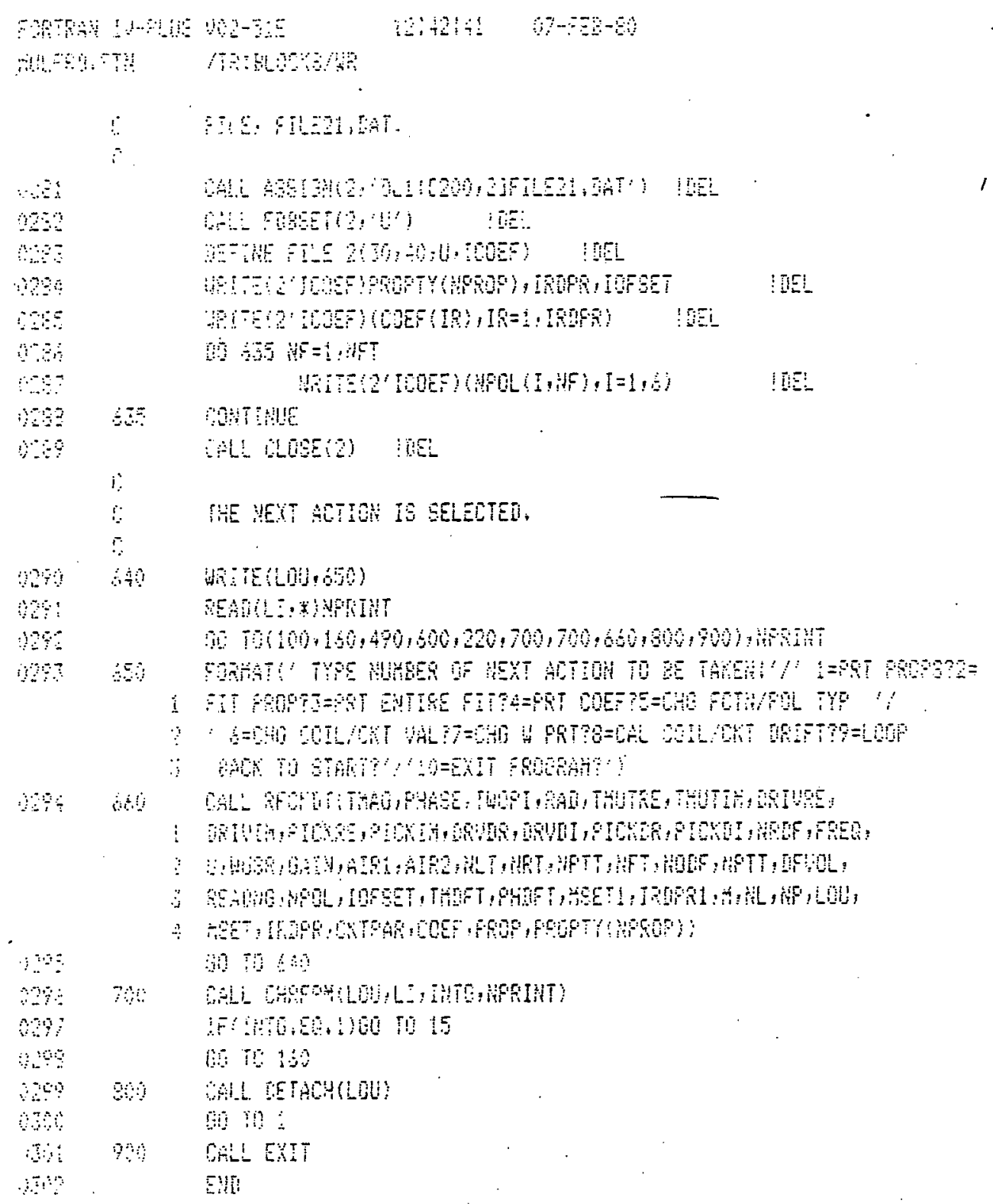




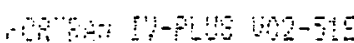

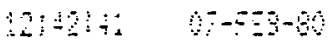

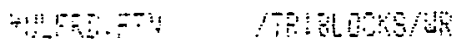

mont SET

\begin{tabular}{|c|c|c|c|}
\hline OEF & 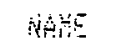 & 81 & \\
\hline$\vdots$ & bous & $\because 900$ & 282 \\
\hline$\because$ & PFIATHA & 0015 & 53 \\
\hline$z$ & ITHA & moth & 798 \\
\hline$\therefore$ & $7+5$ & ACIAL & 10967 \\
\hline 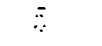 & STEWE & 00064 & 17 \\
\hline$\because$ & 5 & mol & 5 \\
\hline 7 & 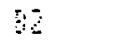 & 60118 & 30 \\
\hline$\overline{3}$ & 56 & b0014 & 6 \\
\hline
\end{tabular}

औTก:บ1

Fis?

m, I, Gu,

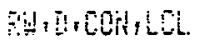

Her iontile

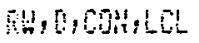

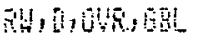

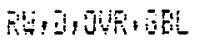

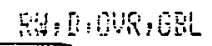

Watisteg

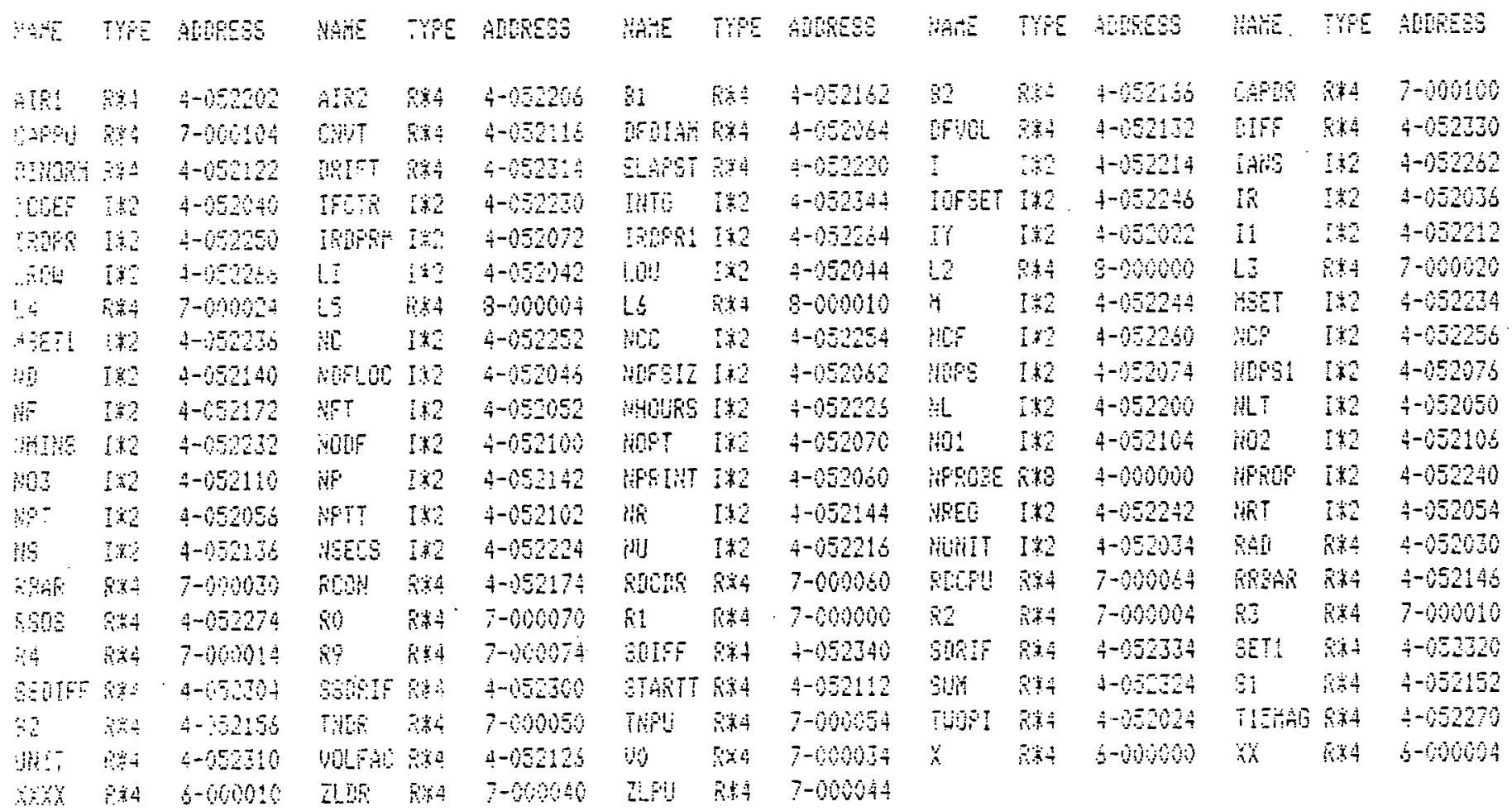

H⿻15

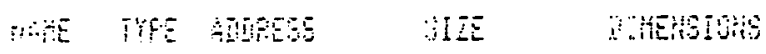

\begin{tabular}{|c|c|c|c|c|}
\hline 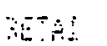 & $8:$ & $\therefore-10104$ & $10002=$ & $\vdots$ \\
\hline FAs & St4 & $4-8564$ & $b_{0}$ & 19 \\
\hline 39045 & ن & $4-600$ & mon & \\
\hline 8 & $F$ & - & بn: & \\
\hline ; & $\because 2$ & $-400:$ & 1000 & \\
\hline & 3 & $\therefore-41 \therefore=8$ & 60104 & 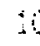 \\
\hline & 7 & $2-4+105$ & 00004 & \\
\hline $60^{\circ}$ & 8 & 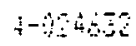 & 001140 & \\
\hline 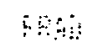 & ; & $4-324472$ & 100140 & \\
\hline & 4 & $1-190$ & 000140 & \\
\hline & 34 & $4-9+112$ & 09010 & \\
\hline
\end{tabular}




\begin{tabular}{|c|c|c|c|c|c|}
\hline 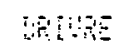 & $\pi 4$ & $i-1092$ & Wa $=0$ & 432 & 3 \\
\hline 910! & $\mathrm{Ni}$ & $f-1+5=2$ & 601540 & 42 & \\
\hline חก, & 84 & $4-14+2$ & 003540 & 432 & 13 \\
\hline 50 & 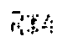 & $\triangle-0,47 / 2$ & \$01: & 6 & (3) \\
\hline$i_{M} !$ & $\%$ & $-12=0 \mathrm{n}$ & bonts & 3 & (3) \\
\hline Moli & 514 & 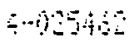 & $600 \div \div 0$ & 40 & (24) \\
\hline$\therefore A r$ & 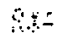 & $4-13532$ & 00149 & 48 & 24 \\
\hline sAtin: & 34 & $4-00162$ & $090: 40$ & 48 & $24\}$ \\
\hline$B A+5$ & 84 & $4-02002$ & $601+0$ & 48 & (24) \\
\hline :1: & 34 & $4-00002$ & 600010 & 4 & $2:$ \\
\hline tif:? & it & $4-0003$ & 00010 & 4 & (2) \\
\hline mait & $\$$ & $4-00010$ & 006011 & 4 & $(9)$ \\
\hline הניח & Wo & $4-900042$ & 900010 & 4 & $(4)$ \\
\hline का & wz & $4-016102$ & 000044 & 15 & $(0.3)$ \\
\hline Minc & $i_{2}$ & $4-02442$ & 100060 & 24 & $(2+)$ \\
\hline H & 都 & $4-417346$ & 00740 & 240 & $(5,24)$ \\
\hline 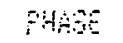 & 84 & $4-62702$ & motso & 43 & $(3,24,3)$ \\
\hline HOT & 14 & $4-01006$ & 300014 & $\frac{b}{3}$ & (3) \\
\hline Bunj & 24 & $4-65052$ & 001540 & 432 & $(3,2+3)$ \\
\hline 00 & $\because 4$ & $4-1,4902$ & $604=0$ & 432 & \\
\hline PUTH & मिं & $4-14146$ & 601540 & 432 & $(3,243)$ \\
\hline MNE & 84 & $4-13772$ & 001540 & 432 & $(3,24,3$ \\
\hline Put & $\because 4$ & $4-91130$ & $\$ 0000$ & 150 & $(16,5)$ \\
\hline 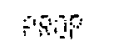 & 34 & $\because-412062$ & 000440 & $1+4$ & $\{72\}$ \\
\hline $00 \%$ & Fit & $4-60032$ & 000030 & 12 & (6) \\
\hline Wndis & 34 & $4-10022$ & 011100 & 233 & $(73,16)$ \\
\hline $\mathrm{cs}$ & अ4 & $4-016006$ & 000740 & 240 & $(5,24)$ \\
\hline$n$ & ma & $4-121246$ & 000740 & 240 & $(5,24)$ \\
\hline 列: & 54 & $4-012522$ & 000014 & 6 & $(3)$ \\
\hline a & 慗4 & $4-012536$ & 600014 & $j$ & $(3)$ \\
\hline $7 B$ & 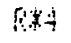 & $4-0,530$ & 000024 & 10 & (5) \\
\hline 7 & $1+\frac{3}{4}$ & $4-1231+5$ & 000740 & 340 & $(5,24)$ \\
\hline Bhot & Bat & $4-120=00$ & 600740 & 240 & $(5,24)$ \\
\hline 4 & Fin: & $4-4002$ & 001540 & 43 & 132493 \\
\hline RBST & 84 & $4-416052$ & onth & 6 & 3 \\
\hline MI:- & $8 \div$ & $4-9062$ & 01500 & 432 & 6243 \\
\hline 7. & $\mathrm{nat}$ & $4-03112$ & $10: 50$ & 432 & 42433 \\
\hline 1 & 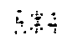 & $4-42206$ & 1000740 & 240 & $(5,24)$ \\
\hline ; & $5 \times 4$ & $4-0002$ & 000030 & 12 & (6) \\
\hline W10 & $n$ & $4-00152$ & 60060 & $\because$ & $(6,2)$ \\
\hline Wh & 踏: & $4-0: 20$ & 101500 & 364 & $16,24,3$ \\
\hline nt & 5 & $\div-01630$ & 00024 & 10 & $(5)$ \\
\hline
\end{tabular}

Hes:

\begin{tabular}{|c|c|c|c|c|c|c|c|c|c|}
\hline 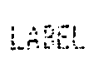 & $\sin 0$ & LAEL & Angess & LAEL & Armins & BnEL & ADESS & LAEE & ADMES \\
\hline$\therefore$ & $1-7020$ & $z^{\prime} \quad \ldots$ & $3-700000$ & $10^{\prime}$ & $5-100006$ & 15 & $1-901034$ & 70 & to \\
\hline$a$ & $5-9006$ & 3 & $1-001350$ & 30 & a & 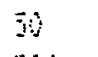 & 郭 & 6 & $1-600$ \\
\hline 78 & 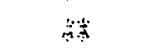 & 80 & $i-102510$ & 85 & 5 & $w^{\prime}$ & $3-1000062$ & 100 & $1-03=2$ \\
\hline $10^{\prime}$ & $3-00014 \div$ & 120 & $1-104932$ & $1.30^{\prime}$ & $3-000314$ & $4 i^{\prime}$ & $3-00035$ & $\left(50^{\circ}\right.$ & $3-006306$ \\
\hline 130 & $1-i p+22 \hat{0}$ & 170 & $4 \mathrm{x}$ & $130^{\circ}$ & $5-000410$ & $170^{i}$ & $5-00057$ & 200 & 䋨 \\
\hline 210 & \% & 220 & $1-0,5052$ & $230^{\circ}$ & $3-600662$ & 240 & 当 & $230^{\prime}$ & $5-60742$ \\
\hline $260^{\circ}$ & $3-60194$ & 360 & 林 & $310^{\prime}$ & $3-901202$ & 32 & $3-00125$ & $330^{\prime}$ & $5-01302$ \\
\hline
\end{tabular}




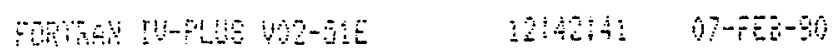

Hithiti:

\begin{tabular}{|c|c|c|c|c|c|c|c|c|c|}
\hline 80 & $1-16944$ & $74^{2}$ & $5-601532$ & 345 & $5-101+40$ & 50 & 絖 & 37 & $\mathrm{~s}^{2}$ \\
\hline $4 \omega^{\prime}$ & $3-04+2$ & 450 & $y$ & 400 & $\Leftrightarrow$ & 47 & 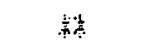 & \pm 80 & 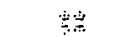 \\
\hline 570 & -4003 & $m$ & $=-601474$ & 520 & s. & 50 & $\dddot{m}$ & 340 & \% \\
\hline $560^{\prime}$ & $5-00 \mathrm{i}=2$ & 30 & $1-007400$ & 880 & 8 & 585 & $1-90750$ & $5 n^{\prime}$ & $5-001604$ \\
\hline$\infty$ & -607542 & $6 \hat{0}$ & $\mathrm{si}$ & 635 & 站 & 640 & $1-010350$ & $\sin$ & $7-601572$ \\
\hline 60 & $1-9004$ & 700 & $1-010 \div 50$ & 500 & -410514 & 760 & $1-01050$ & & \\
\hline
\end{tabular}

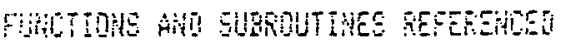

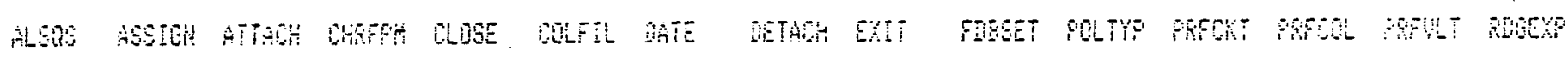

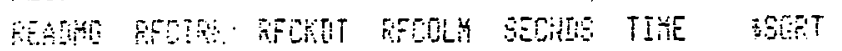

THAL SFAE ALLGTEQ $=0.60014015$

arian $=4040$ 
BDX-613-2482

EXPERIMENTAL MODELING OF LAMINAR COMPOSITES FOR MULTIFREQUENCY EDDY CURRENT MEASUREMENTS, R. V. Heckman, Milestone, August 1980

This report describes a computor modeling program, originally developed by Dodd and Deeds of Oak Ridge National Laboratory, capable of calculating the experimental voltage amplitudes and phases which can be obtained with rectangular cross-section coils being operated at multiple frequencies. This program was applied to two multilayered composites in order to determine the feasibility of making thickness and resistivity measurements of the individual layers. The results of

SPECIAL PROJECTS: Measurement

EXPERIMENTAL MODELING OF LAMINAR COMPOSITES FOR MULTIFREQUENCY EDDY CURRENT MEASUREMENTS, R. V. Heckman, BDX-613-2482, August 1980

This report describes a computor modeling program, originally developed by Dodd and Deeds of Oak Ridge National Laboratory, capable of calculating the experimental voltage amplitudes and phases which can be obtained with rectangular cross-section coils being operated at multiple frequencies. This program was applied to two multilayered composites in order to determine the feasibility of making thickness and resistivity measurements of the individual layers. The results of

EXPERIMENTAL MODELING OF LAMINAR COMPOSITES FOR MULTIFREQUENCY EDDY CURRENT MEASUREMENTS, R. V. Heckman, BDX-613-2482, August 1980 This report describes a computor modeling program, originally developed by Dodd and Deeds of Oak Ridge National Laboratory, capable of calculating the experimental voltage amplitudes and phases which can be obtained with rectangular cross-section coils being operated at multiple frequencies. This program was applied to two multilayered composites in order to determine the feasibility of making thickness and resistivity measurements of the individual layers. The results of of 
these calculations indicate that the thickness of the aluminum/kapton composite layers could be measured to a precision of better than one percent and the resistivity of the conductive layers could be measured to a precision of better than ten percent. The second composite, a structure consisting of alternating layers of aluminum and polyimide, a varnish, was found to be measureable also. A minimum of two frequency components were found to be necessary for the aluminum/kapton composite while three frequencies were found to be necessary for the aluminum polyimide case.

these calculations indicate that the thickness of the aluminum/kapton composite layers could be measured to a precision of better than one percent and the resistivity of the conductive layers could be measured to a precision of better than ten percent. The second composite, a structure consisting of alternating layers of aluminum and polyimide, a varnish, was found to be measureable also. A minimum of two frequency components were found to be necessary for the aluminum/kapton composite while three frequencies were found to be necessary for the aluminum polyimide case.

these calculations indicate that the thickness of the aluminum/kapton composite layers could be measured to a precision of better than one percent and the resistivity of the conductive layers could be measured to a precision of better than ten percent. The second composite, a structure consisting of alternating layers of aluminum and polyimide, a varnish, was found to be measureable also. A minimum of two frequency components were found to be necessary for the aluminum/kapton composite while three frequencies were found to be necessary for the aluminum polyimide case. 